\title{
Toward reduction of the uncertainties in climate sensitivity due to cloud processes using a global non-hydrostatic atmospheric model
}

Masaki Satoh $^{1 *}$ D, Akira T. Noda ${ }^{2}$, Tatsuya Seiki ${ }^{2}$, Ying-Wen Chen ${ }^{1}$, Chihiro Kodama², Yohei Yamada², Naomi Kuba ${ }^{1}$ and Yousuke Sato ${ }^{3,4}$

\begin{abstract}
In estimates of climate sensitivity obtained from global models, the need to represent clouds introduces a great deal of uncertainty. To address this issue, approaches using a high-resolution global non-hydrostatic model are promising: the model captures cloud structure by explicitly simulating meso-scale convective systems, and the results compare reasonably well with satellite observations. We review the outcomes of a 5-year project aimed at reducing the uncertainty in climate models due to cloud processes using a global non-hydrostatic model. In our project, which was conducted as a subgroup of the Program for Risk Information on Climate Change, or SOUSEl, we use the non-hydrostatic icosahedral atmospheric model (NICAM) to study cloud processes related to climate change. NICAM performs numerical simulations with much higher resolution (about $7 \mathrm{~km}$ or $14 \mathrm{~km}$ mesh) than conventional global climate models (GCMs) using cloud microphysics schemes without a cumulus parameterization scheme, which causes uncertainties in climate projection.

The subgroup had three research targets: analyzing cloud changes in global warming simulations with NICAM with the time-slice approach, sensitivity of the results to the cloud microphysics scheme employed, and evaluating circulation changes due to global warming. The research project also implemented a double-moment bulk cloud microphysics scheme and evaluated its results using satellite observation, as well as comparing it with a bin cloud microphysics scheme. The future projection simulations show in general increase in high cloud coverage, contrary to results with other GCMs. Changes in cloud horizontal-size distribution size and structures of tropical/extratropical cyclones can be discussed with high resolution simulations. At the conclusion of our review, we also describe the future prospects of research for global warming using NICAM in the program that followed SOUSEl, known as TOUGOU.
\end{abstract}

Keywords: NICAM, Cloud microphysics scheme, Cloud changes, Cloud feedback, Global non-hydrostatic model, Global warming

\footnotetext{
* Correspondence: satoh@aori.u-tokyo.ac.jp

${ }^{1}$ Atmosphere and Ocean Research Institute, The University of Tokyo, 5-1-5

Kashiwanoha, Kashiwa, Chiba 277-8568, Japan

Full list of author information is available at the end of the article
} 


\section{Introduction}

The representation of clouds is widely regarded as the largest source of uncertainty in estimates of climate sensitivity obtained by global climate models (GCMs) (Boucher et al. 2013; Soden and Held 2006; Dufresne and Bony 2008; Vial et al. 2013; Schneider et al. 2017; Zelinka et al. 2017). A useful approach to reduce the uncertainties associated with the simulation of clouds is to develop appropriate cloud schemes for very fine resolution global models and evaluate them with observed data particularly from satellite remote sensing (Bony et al. 2015; Klein and Hall 2015).

The Program for Risk Information on Climate Change (referred to as the SOUSEI program ${ }^{1}$ ) was promoted by the Japanese Ministry of Education, Culture, Sports, Science and Technology (MEXT) from October 2012 to March 2017 with the aim of generating the basic information required to manage the various risks resulting from climate change. Using world-class supercomputers, such as Earth Simulator ${ }^{2}$, the SOUSEI program conducted research and development across four linked themes: (A) prediction and diagnosis of imminent global climate change expected to occur within a few years or decades, (B) research on greenhouse gas emission scenarios and associated long-term climate change projections, (C) development of probabilistic climate change projection techniques, and (D) development of technology for precise impact assessment of climate change. Under theme A, a subgroup focused on reducing the uncertainty in climate models due to cloud processes using a global non-hydrostatic icosahedral atmospheric model (NICAM; Tomita and Satoh 2004; Satoh et al. 2008, 2014); we refer to it as the NICAM subgroup.

NICAM has been used for more than a decade to assess atmospheric changes due to global warming (Satoh et al. 2014, 2017). Because of its high resolution, NICAM is expected to provide more information about multi-scale convective systems such as tropical cyclones (TCs) and Madden-Julian oscillations, compared to currently used coarser resolution GCMs. NICAM can also be used with an explicit cloud microphysics scheme and without a convective parameterization scheme to realistically reproduce the structure of meso-scale convective systems which compare reasonably well with satellite observations (Hashino et al. 2013, 2016).

However, the use of NICAM for climate studies has been limited because computational resources were not sufficiently powerful to simulate longer integrations on a climate scale. Yamada et al. (2010) and Yamada and Satoh (2013) examined NICAM projections of the response of simulated TCs to imposed future global warming conditions. Thanks to the growth in computing power in the past decade (Satoh et al. 2017), multi-decadal simulations using NICAM have been achieved with horizontal resolutions of about $14 \mathrm{~km}$ (Kodama et al. 2015; Satoh et al. 2015; Yamada et al. 2017).

The aims of the NICAM subgroup, which comprised the authors of this review, were aligned with the demand for a more comprehensive understanding of cloud processes proposed by Bony et al. (2015). The research was focused on three themes. First, as a basis for global non-hydrostatic climate simulations, we implemented a newly developed double-moment bulk cloud microphysics scheme with six water categories (NDW6; originally described by Seiki and Nakajima 2014), which is suitable for the analysis of cloud radiation feedback. We evaluated the results of the new scheme using satellite observations and compared it with other cloud microphysics schemes, including a bin scheme, to understand the uncertainties related to cloud microphysics schemes. Second, we analyzed the cloud changes due to global warming in simulations using NICAM with the new version of NDW6 and compared the results to those of other microphysics schemes. Third, we analyzed changes in circulation due to global warming, particularly features as cloud system organization, storm tracks, and TCs.

\section{Review}

Here, we review the development of a new cloud microphysics scheme and compare it with other cloud microphysics schemes, particularly using a large-eddy simulation model and a kinematic driver. We analyze the NICAM simulation results in terms of clouds and circulation changes by comparing the simulations under present-day and global warming scenarios. We also present an analysis of cloud changes, sensitivities to cloud microphysics schemes, and changes in storm tracks and TCs.

\section{Development of a double-moment cloud microphysics scheme}

Efforts to improve a cloud microphysics scheme for NICAM face particular challenges. Here, we focus on improving global simulations of high clouds by elaborating ice cloud microphysics and refining model horizontal and vertical resolution. Most GCMs in the Coupled Model Intercomparison Project Phase $5\left(\mathrm{CMIP}^{3}\right)$ had large uncertainty in ice water content (IWC) in the upper troposphere (Waliser et al. 2009; Jiang et al. 2012; $\mathrm{Li}$ et al. 2012). This uncertainty is expected to cause large biases in longwave cloud radiative forcing (LWCRF), because high clouds are known to make a large positive contribution to the total LWCRF (Jensen et al. 1994). Flato et al. (2013) showed that LWCRF in the tropics and mid-latitude varied considerably among individual GCMs. Common biases in LWCRF are 
apparent in simulated results from GCMs of both the Coupled Model Intercomparison Project Phase 3 (CMIP3) and CMIP5 (Li et al. 2013), so the cloud processes related to the LWCRF over such regions have hindered the accuracy of GCMs. In the SOUSEI program, we improved the NICAM double-moment bulk cloud microphysics scheme with six water categories (NDW6). The formula of the cloud microphysics processes in NDW6 mainly follows that described by Seifert and Beheng (2006) (hereafter referred to as the SB scheme) and was implemented into NICAM by Seiki and Nakajima (2014) with minor modifications. The key characteristics of the SB scheme are consistency between particle size distributions and growth equations: tendencies of the number and mass concentration are derived by integrating theoretical particle growth equations weighted by particle size distributions. In addition to the SB scheme, Seiki and Nakajima (2014) designed consistency between the particle shape, terminal velocity, and growth equation. The self-consistency results in a decrease in uncertainties in NDW6, and hence, is important for global climate simulations. The cloud microphysical processes solved in NDW6 are schematically illustrated in Fig. 1, and details of the development of NDW6 are described in the "Appendix" section.

\section{Cloud microphysics schemes used in NICAM}

NICAM has been used to understand the roles of convective clouds, particularly over the tropics, in climate systems and the response of such clouds to global warming. For this purpose, single-moment bulk cloud microphysics schemes (referred to here as SMs) have been used in NICAM simulations because changes in mass concentration of precipitating hydrometeors and associated latent heat release, which are explicitly calculated by SMs, involve dynamical feedback to cloud development such as cold pool and precipitation drag.

NICAM can be used with various SMs (Kessler 1969; Grabowski 1998; Lin et al. 1983; Hong et al. 2004; Tomita 2008). In particular, the NICAM single-moment bulk cloud microphysics scheme with six water categories (NSW6) developed by Tomita (2008), which predicts the mass concentration of vapor, cloud water, rain, cloud ice, snow, and graupel, has been evaluated by comparing with multi-satellite observations (Satoh et al. 2010; Kodama et al. 2012; Hashino et al. 2013, 2016). Roh and Satoh (2014) improved NSW6 by examining the diagnosis of particle size distribution and ice cloud microphysics related to snow and graupel. Using their scheme, the simulated vertical profiles of precipitating hydrometeors were in good agreement with those of the Tropical Rainfall Measuring Mission (TRMM) and CloudSat satellite observations (Roh et al. 2017).

Cloud microphysics schemes in NICAM have been improved to simulate persistent clouds, such as cirrus clouds, or light snow over the tropics and mid-latitude, because such high clouds have large impacts on LWCRF (Chen et al. 2000). For this purpose, during the SOUSEI program, we improved the ice cloud microphysics in the original NDW6 developed by Seiki and Nakajima (2014). In general, double-moment bulk cloud microphysics schemes (referred to here as DMs) predict the number concentration of hydrometeors as well as their mass concentration, and so, more precisely represented the evolution of particle size distribution in cloud growth over time compared with SMs. As a result, DMs can capture the transition of cloud systems from weak or moderate organization to a strong convective phase,

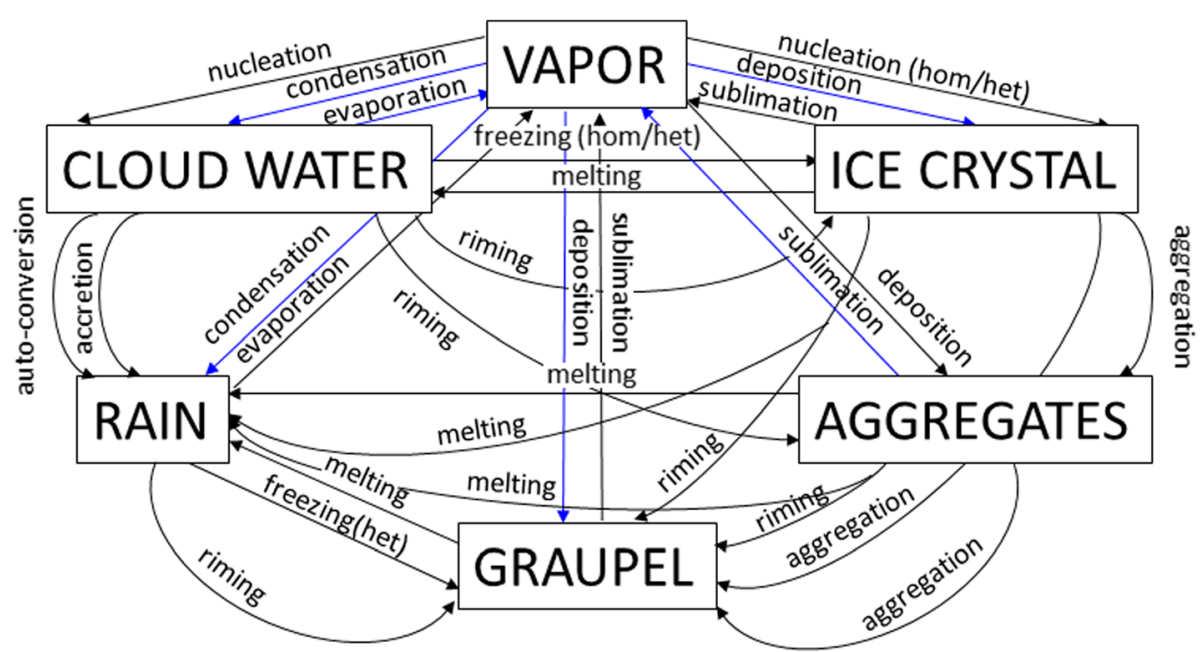

Fig. 1 Schematic representation of cloud microphysical processes solved in NDW6. Black lines show the processes that change the number and mass concentrations of hydrometeors, while blue lines show the processes that change only the mass concentrations of hydrometeors. Hom: homogenous, het: heterogenous 
whereas SMs are often optimized for capturing the mature stage of convective systems. Other differences between SMs and DMs are discussed by Igel et al. (2015).

\section{Global simulations using NDW6}

During the SOUSEI program, global simulations using NICAM with NDW6 were conducted and evaluated. Figure 2 shows the zonal mean values of simulated outgoing longwave radiation (OLR) at the top of the atmosphere using NSW6 and different versions of NDW6 averaged over the last 5 days of the simulation period. The simulation was conducted for 10 days initiated from 15 June 2008; the 10-day simulation period is sufficient for spin-up of the response of cloud distribution to changes in cloud microphysical settings (e.g., Kodama et al. 2012). The development of various version of NDW6 is described in the Appendix and summarized in Table 1 . The OLR is a good proxy for evaluating the global distribution of cirrus clouds because of their strong LWCRF. For reference, satellite observations from the Clouds and the Earth's Radiant Energy System (CERES) level3 SYN1deg_Ed3A product (Doelling et al. 2013) are superimposed (Fig. 2). The global average OLR of the observation was $241.72 \mathrm{~W} \mathrm{~m}^{-2}$ in this period. The deviation of the global averaged OLR of each simulation from the observation was $3.08,-18.44,-2.50$, $1.13,4.62$, and 3.76 for NSW6, SN14, S14, S15, $\mathrm{S} 15 \mathrm{~V}$, and $\mathrm{S} 15 \mathrm{VH}$, respectively (refer to the Appendix and Table 1 for the meaning of these symbols).

The NICAM simulation with NSW6 originally had a large bias in OLR and was optimized by Kodama et al. (2012) to reduce the global averaged bias by changing the aggregation efficiency and terminal velocity of cloud ice (see Fig. 2a). The bias in OLR was globally significant in SN14 (see Fig. 2b) because NDW6 had not been used for global simulations at that time. From SN14 to S14, this severe bias was reduced by changing the heterogeneous ice nucleation scheme (Seiki et al. 2014). These studies demonstrated that optimization of OLR using in situ observation was also effective for global simulations (Figs. 2b, c). From S14 to S15, minor improvements in OLR are shown (Figs. 2c, d). In NSW6, S14, and S15, a positive bias over the tropics and a negative bias over the sub-tropics were commonly observed and compensated for each other, so the global averaged bias was relatively small. Seiki et al. (2015b) found that the negative bias over the sub-tropics originated from thin cirrus clouds near the tropopause and decreased as the vertical resolution increased up to $400 \mathrm{~m}$ (Fig. 2e). Furthermore, Seiki et al. (2015b) suggested that the positive bias over the tropics was sensitive to horizontal resolution (Fig. 2f) and could therefore be resolved by increasing the horizontal resolution to finer than $7 \mathrm{~km}$ to represent convective clouds over the tropics. In terms of the geographical distribution of OLR values, S15VH reduced the bias over both the tropics and sub-tropics. On the basis of these results, we currently believe that $\mathrm{S} 15 \mathrm{VH}$ is the best NDW6 for reproducing OLR.

The global simulation of cirrus clouds was also evaluated by comparing to CALIPSO and CloudSat satellite observations with a satellite simulator named the Joint Simulator for Satellite Sensors (Hashino et al. 2013). Within the simulation period, S15VH closely reproduced the vertical profiles of IWC, ice number concentration (NI), and ice effective radius (REI) (Seiki et al. 2015b).

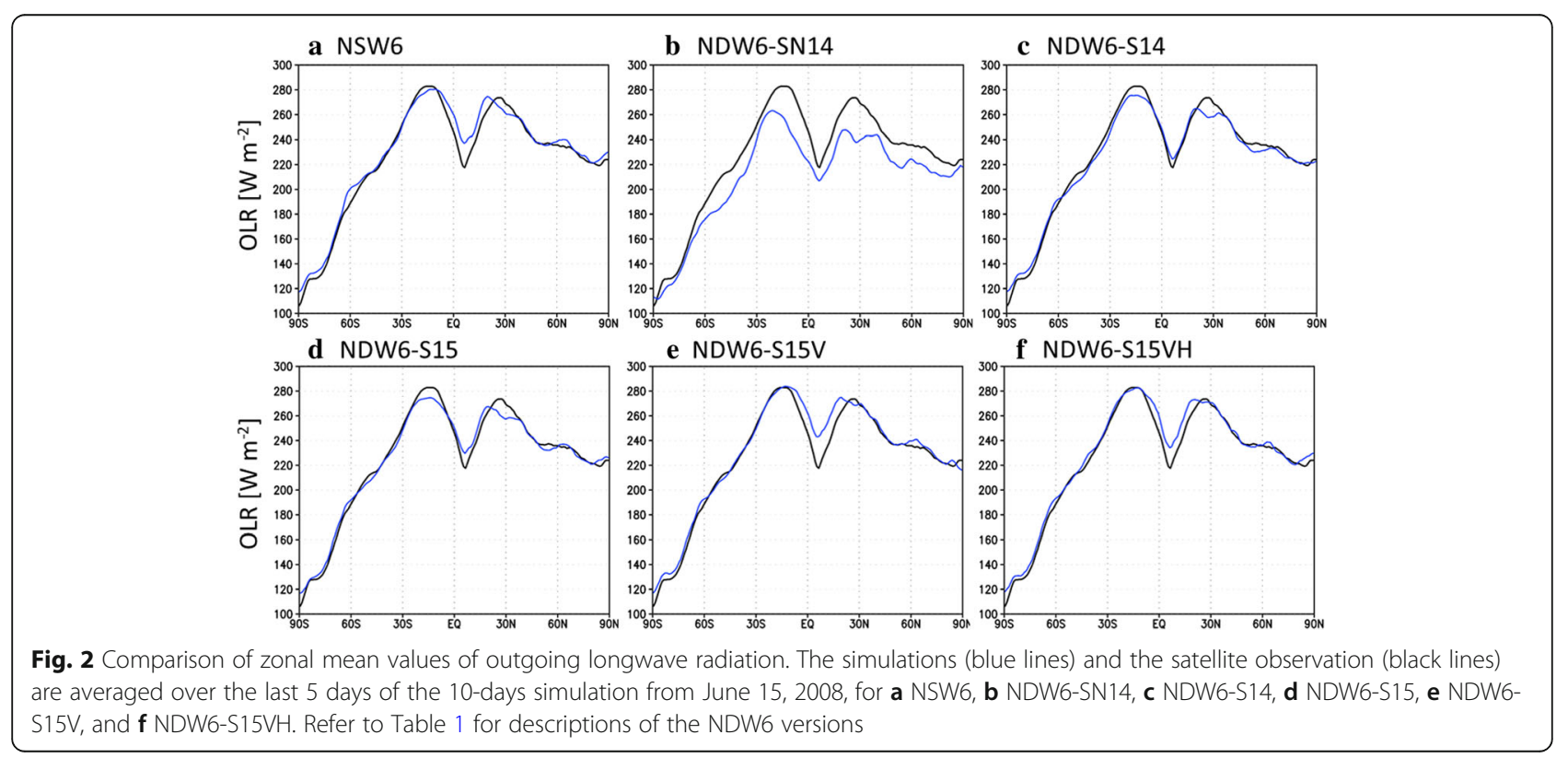


Table 1 Summary of different versions of NDW6

\begin{tabular}{ll}
$\begin{array}{l}\text { Abbreviated name (reference } \\
\text { paper) }\end{array}$ & Main features \\
\hline $\begin{array}{l}\text { SN14 (Seifert and Beheng 2006; } \\
\text { Seiki and Nakajima 2014) }\end{array}$ & $\begin{array}{l}\text { Minor changes from Seifert and Beheng (2006): the power law relationships between } x \text { and } D \text { and between } x \text { and } A \\
\text { are assumed and the terminal velocity is diagnosed using } x, D \text {, and } A \text {. } \\
\text { S14 (Seiki et al. 2014) }\end{array}$ \\
Cloud optical properties are updated from Mie scattering to non-spherical scattering. The heterogeneous ice \\
nucleation scheme proposed by Meyers et al. (1992) is replaced by the scheme proposed by Phillips et al. (2007). \\
S15 (Seiki et al. 2015b)
\end{tabular}

Seiki et al. (2015a) performed seasonal global simulations using S14 and compared them with the simulations produced using NSW6 by Kodama et al. (2012) to examine improvements in atmospheric state via cirrus cloud radiative forcing after feedback of dynamics to cloud distribution. The simulations were initiated from 1 June 2004 and were integrated for 3 months. Seiki et al. (2015a) found that NSW6 had severe warm bias over the tropics, which was more than $2 \mathrm{~K}$ in the entire free troposphere and up to $7 \mathrm{~K}$ near the tropopause. This bias was also found in 20-year simulations (Kodama et al. 2015) and hence was robust when using NSW6. Using NDW6, this bias was significantly reduced by $4 \mathrm{~K}$ on average in the free troposphere because NDW6 accurately represent the spatial distribution of cirrus clouds, particularly near the tropopause (200 to $100 \mathrm{hPa}$ ), and the LWCRF of cirrus cloud. Kodama et al. (2015) found that the auto-conversion of cloud ice to snow was the key to reproducing cirrus clouds and their LWCRF. The auto-conversion was generally modeled by a decay equation of cloud ice with an empirical timescale for ease of tuning. The threshold of the mixing ratio of cloud ice to initiate the conversion and the timescale are necessarily assumed as global constants in SMs. Seiki et al. (2015b) noted that the conversion rate strongly depends on the cross section, terminal velocity, and number concentration of ice particles based on the theory of cloud microphysics. NDW6 realistically simulated the auto-conversion of cloud ice to snow by solving a theoretical collection equation, with predicted mass concentration and number concentration of hydrometeors. Since the auto-conversion process was sensitive to the simulated amount of cloud ice, which could persist near the tropopause, such an empirical formulation used for SMs should be avoided for more precise calculations of cloud and radiation feedback.

In the SOUSEI program, NDW6 was shown to more realistically simulate cirrus clouds, making it suitable for global long-term simulations of climate studies. Cloud radiative properties should be refined by improving ice cloud microphysics. We mainly used OLR as a proxy of bulk structure of ice clouds, such as the spatial distribution of cirrus clouds. The shortwave (SW) radiation and backscattered radar/lidar signals were sensitive to cloud microphysical structures such as IWC, NI, REI, and the shape of ice particles. Improvement in ice cloud microphysics and the refinement of the model's spatial resolution were important for reducing bias in the global radiation budget and atmospheric temperature (Seiki et al. 2015a, b). Despite developing a new and improved cloud microphysics scheme, the continuous development of cloud microphysics schemes is still necessary. For example, our cloud microphysics schemes assumed at most five categories of hydrometeors (Fig. 1) although various ice species were modeled for atmospheric simulation (Chen and Lamb 1994a, b, 1999; Hashino and Tripoli 2007, 2008, 2011a, b; Harrington et al. 2013a, b). Uncertainties in ice species could be partially constrained by comparing simulated results with satellite observations (e.g., Li et al. 2010; Lang et al. 2014). Efforts are underway to couple NDW6 with aerosol transport models to focus on the effects of aerosols on the ice nucleation process, as suggested by Seiki et al. (2014), but we do not cover that work here.

\section{Sensitivity of cloud microphysics schemes}

A cloud microphysics scheme is at the heart of cloud-resolving models. Cloud-resolving simulations that represent clouds using a cloud microphysics scheme aid in reducing the uncertainties in climate predictions related to clouds. SMs have been implemented in NICAM and have been used in global-scale cloud-resolving simulations; an SM by Grabowski (1998) and NSW6 by Tomita (2008) are mostly commonly used, such as by Miura et al. (2007) and Kodama et al. (2015), respectively. However, DMs or more sophisticated schemes are required to appropriately calculate cloud and radiation processes and the effects of aerosols on clouds (Grabowski and Morrison 2016). NDW6 was implemented in NICAM following Seiki and Nakajima (2014) and has 
been improved further, as discussed earlier in this review. In addition to NDW6, a spectral bin scheme by Suzuki et al. (2010a) has been implemented in NICAM and is now being tested. However, it is not easy to conduct global cloud-resolving simulations coupled with a spectral bin scheme due to limitations in the currently available computing power.

Simple models, such as a single-column model (e.g., Guo et al. 2011; Suzuki et al. 2015) and a kinematic model (e.g., the Kinetic Driver model or KiD; Shipway and Hill 2012), have been used to investigate the sensitivity of cloud microphysics schemes and to interpret their differences. Although these simple models enable us to interpret the differences of cloud microphysics schemes easily, they ignore atmospheric cloud feedback processes. To help us understand the sensitivity of cloud microphysics schemes including feedback processes, idealized fine-resolution simulations have been conducted using large-eddy simulation (LES) models.

\section{Sensitivity using a large-eddy simulation model}

LES models provide an additional approach to examine the differences between cloud microphysics schemes. However, because LES models have a large computational cost due to their fine spatial grid resolution, they have been used mainly for numerical simulations targeting shallow clouds in a limited domain. A number of intercomparison studies using LES models have been conducted (e.g., Bretherton et al. 1999a, b; Siebesma et al. 2003; Stevens et al. 2001, 2005; Ackerman et al. 2009; van Zanten et al. 2011; Blossey et al. 2013). These intercomparison studies showed that the results of the LES models have large variability in general. Among them, van Zanten et al. (2011) claimed that the cloud microphysical scheme is one of the main sources of this variability. However, their study is based on the results of several models with their own dynamical cores and physical schemes, which include different turbulent schemes and cloud microphysical schemes. Thus, it is difficult to identify the cause of the variability.

To overcome this difficulty, Sato et al. (2015) investigated the sensitivity of cloud microphysics schemes to trade wind cumulus simulated by an LES model with interchanging cloud microphysics schemes. They used an LES model included in Scalable Computing for Advanced Library and Environment (SCALE; Nishizawa et al. 2015; Sato et al. 2015). The configuration of the simulations was the same as that used in the intercomparison study, Rain in Cumulus over the Ocean (RICO; van Zanten et al. 2011). The cloud microphysics schemes used were SM, DM, and a spectral bin microphysics scheme (Suzuki et al. 2010a). SM and DM were based on NSW6 and NDW6, respectively, with slight modifications when implementing them in SCALE.
Sato et al. (2015) found that the dependence of the cloud microphysics scheme on vertically integrated liquid water (liquid water path) and cloud cover was small (Figs. 3a, b). By contrast, the vertical profiles of liquid water mixing ratios were very variable (Fig. 3c), which resulted in differences in the turbulent structure of the boundary layer (e.g., Fig. 3d). Their analyses showed that these differences derived mainly from differences in the schemes with respect to the generation of cloud droplets (i.e., activation of aerosols, nucleation of cloud droplets) and the rate of conversion of small cloud droplets to raindrops. A saturation adjustment, which was only applied to the cloud droplet formation process for SMs, generated a large amount of cloud water, which resulted in rapid conversion of cloud droplets to raindrops. As a result of differences in the new-particle generation process, the conversion speeds of SMs and DMs were fast and slow, respectively, and the conversion speed of the spectral bin scheme was somewhere in between. The fast conversion promoted the generation of raindrops and precipitation, which led to the evaporation of raindrops below clouds (sub-cloud layer) and stabilized the boundary layer.

In contrast, when the conversion speed was slow, small cloud droplets remained in the atmosphere and reached upper layers, as small droplets are more easily carried by updrafts compared to large raindrops. With such small droplets, the latent heat of the condensation process was released at higher layers. As a result, in the slow conversion scheme (i.e., DMs), the development of the boundary layer was active, and the boundary layer height was high (Fig. 3c).

The results from these sensitivity simulations suggest potential modifications to improve the simple microphysics scheme (i.e., SMs). In addition, they aid in the interpretation of differences between the results of NICAM coupled with SMs, DMs, and the spectral bin scheme.

\section{Comparison with a bin microphysics scheme}

Another approach to examine sensitivities to cloud microphysics schemes is the use of simplified models without dynamical feedback of cloud microphysics. A kinematic model is widely used to separately examine sensitivities to microphysics processes (Shipway and Hill 2012; Hill et al. 2015). Grabowski (2016) recently proposed a "piggybacking" approach that separates dynamical and microphysical impacts on deep convection.

Kuba et al. $(2014,2015)$ used a two-dimensional kinematic driver model (Shipway and Hill 2012) to study shallow cloud properties simulated by a spectral bin cloud microphysics scheme and examined the differences between NDW6 and the bin scheme; the bin scheme examined here is a cloud microphysical model 

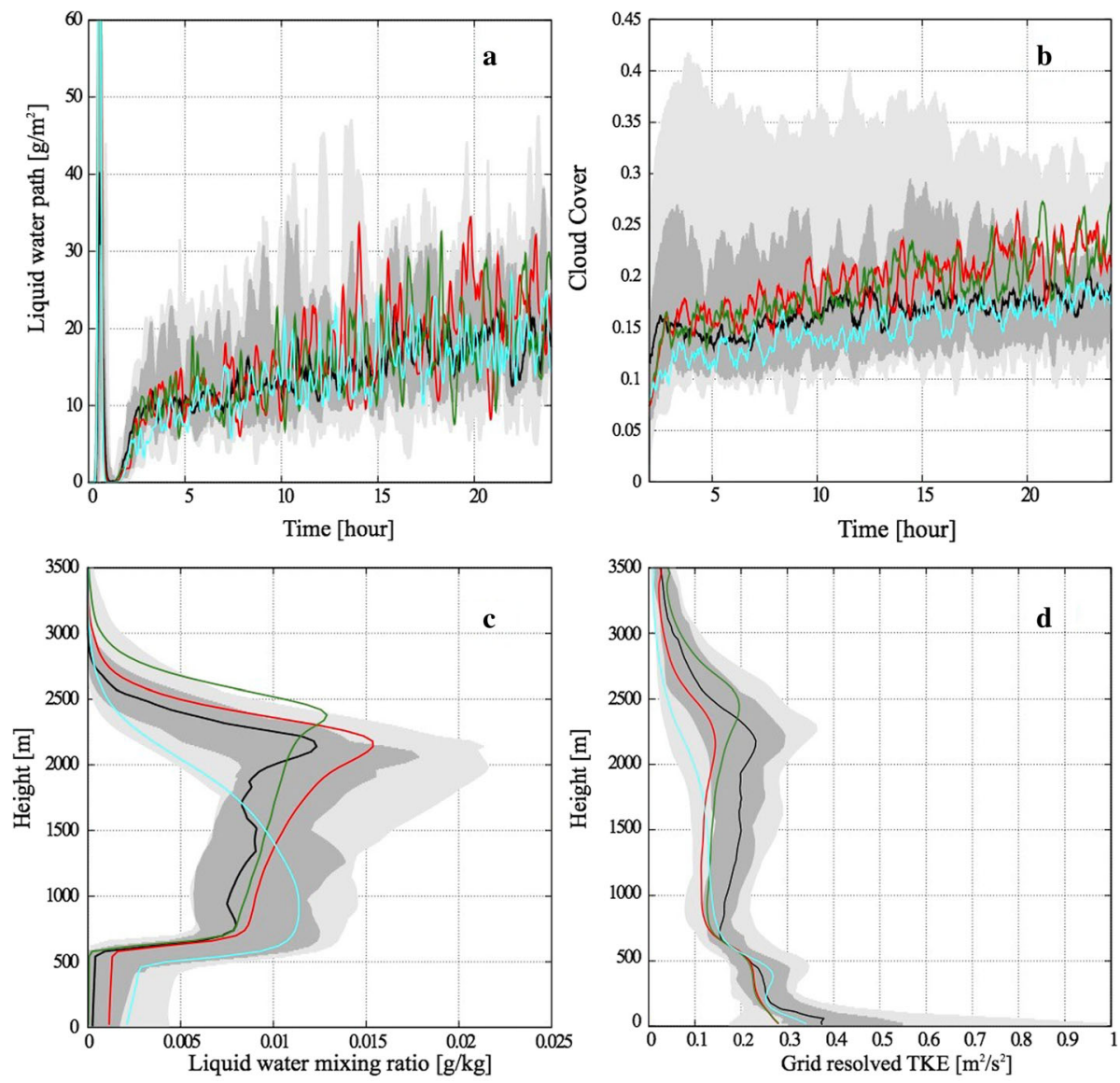

GCSS inter-comparison

Double-moment bulk scheme Spectral bin scheme Single-moment bulk scheme

Fig. 3 Comparison of the bulk cloud microphysics schemes and spectral bin scheme. Time evolution of the $\mathbf{a}$ liquid water path and $\mathbf{b}$ cloud cover, and 4-h averaged vertical profile of $\mathbf{c}$ liquid water mixing ratio and $\mathbf{d}$ grid-resolved turbulent kinetic energy averaged over the entire calculation domain. The red, green, and cyan lines indicate the results of the spectral bin, double-moment bulk cloud microphysics scheme, and single-moment bulk cloud microphysics scheme, respectively. The black line, dark gray shading, and light gray shading indicate the median, range between the first and third quartiles, and range between maximum and minimum values of an intercomparison study of Global Energy and Water EXchange project (GEWEX) Cloud System Study (GCSS), respectively (van Zanten et al. 2011). Adapted from Sato et al. (2015)

with a two-moment bin method based on Kuba and Fujiyoshi (2006) and modified by Kuba and Murakami (2010), and will be referred to as the KF-bin scheme. To investigate the relationships between cloud microphysical processes and satellite observational data, Suzuki and Stephens (2008) examined the relationships between mean radar reflectivity, $Z_{e}$, and mean particle effective radius, $R_{e}$, values for shallow clouds retrieved from satellite observations and used this information to identify warm cloud microphysical processes. Suzuki et al. (2010b) further analyzed the contoured frequency by optical depth (CFODD) for vertical profiles of radar reflectivity as a function of cloud optical depth from cloud top to investigate cloud microphysical processes based on a methodology adapted from Nakajima et al. (2010).

Kuba et al. (2014) reproduced a diagram proposed by Suzuki and Stephens (2008) using a kinematic driver model (Shipway and Hill 2012) with the KF-bin scheme and a forward simulator of satellite measurements. Changes in the size distribution of cloud droplets and raindrops were traced in the two-dimensional kinematic driver model (Shipway and Hill 2012) for a warm cloud. Kuba et al. (2014) calculated radar reflectivity and optical thickness using the numerical data output from this model as the input for the radar simulator developed by Masunaga and Kummerow (2005) in the Joint Simulator for Satellite Sensors (Hashino et al. 2013).

In the $Z_{e}-R_{e}$ diagram reproduced by Kuba et al. (2014), the relationships between $Z_{e}$ and $R_{e}$ follow four paths during the lifetime of warm clouds. In the first path, both $Z_{e}$ and $R_{e}$ increase with an approximate sixth-power dependency, indicating a stage of condensational growth of droplets without raindrops in the clouds. In the second path, $Z_{e}$ increases sharply while $R_{e}$ 
stays almost constant, indicating that few raindrops emerge in the clouds. In the third path, $R_{e}$ increases while $Z_{e}$ stays almost constant, indicating a stage of coalescence of droplets; precipitation reaches the ground at the end of this path. In the fourth path, both $Z_{e}$ and $R_{e}$ decrease, indicating that raindrops evaporate and precipitation weakens.

Kuba et al. (2015) followed Kuba et al. (2014) and investigated the relationships between horizontally averaged radar reflectivity, $Z_{m}$, and cloud optical depth from cloud top, $\tau_{d}$, to examine cloud microphysical processes inferred from the CFODD by Suzuki et al. (2010b) and Sato et al. (2012). Kuba et al. (2015) used the same kinematic model with the KF-bin scheme and the satellite simulator to depict vertical profiles of radar reflectivity of warm clouds in the same way as Kuba et al. (2014). Figure 4 shows the relationship between $Z_{m}$ and $\tau_{d}$ at 2.5-min intervals in cases of continental cloud condensation nuclei (Figs. 4a-d) and maritime cloud condensation nuclei (Figs. 4e-h). This indicates three patterns in the relationships related to cloud microphysical processes. In the first path, $Z_{m}$ increases slightly with a decrease in $\tau_{d}$ or with an increase in altitude (A arrows in Figs. $4 \mathrm{a}, \mathrm{b}, \mathrm{e})$. In the second path, $Z_{m}$ increases with an increase in $\tau_{d}$ in the upper part of cloud (B arrows in Figs. $4 \mathrm{c}, \mathrm{d}, \mathrm{f}-\mathrm{h})$. Then, in the third path, $Z_{m}$ decreases with an increase in $\tau_{d}$ in the lower part of cloud and under the cloud base ( $\mathrm{C}$ arrows in Figs. 4f, g). The cloud microphysical processes affect the relationship between $Z_{m}$ and $\tau_{d}$ (Fig. 4). When $Z_{m}$ increases linearly with a decrease in $\tau_{d}$ (A arrows in Fig. 4), the number of small raindrops increases. This is caused by coalescence between cloud droplets (i.e., the auto-conversion process). When $Z_{m}$ increases with $\tau_{d}$ in the upper part of cloud (B arrows in Fig. 4), the mode radius of raindrops increases. This is caused by coalescence between falling raindrops and cloud droplets (i.e., the accretion process). In the third path, $Z_{m}$ decreases with $\tau_{d}$ in the lower part of cloud and under the cloud base ( $\mathrm{C}$ arrows in Fig. 4). This is caused by a decrease in the number of raindrops with $\tau_{d}$ in the lower part of cloud and under the cloud base (i.e., sedimentation and evaporation). Kuba et al. (2015) also found that the bulk collection efficiency has a partially positive correlation with the slope factor of the relationships between $Z_{m}$ and $\tau_{d}$ (changing rate of $Z_{m}$ to $\tau_{d}$ ) near the cloud top in a later stage of cloud lifetime. Overall, Kuba et al. (2015) reproduced the basic characteristics of the vertical structures of the CFODD

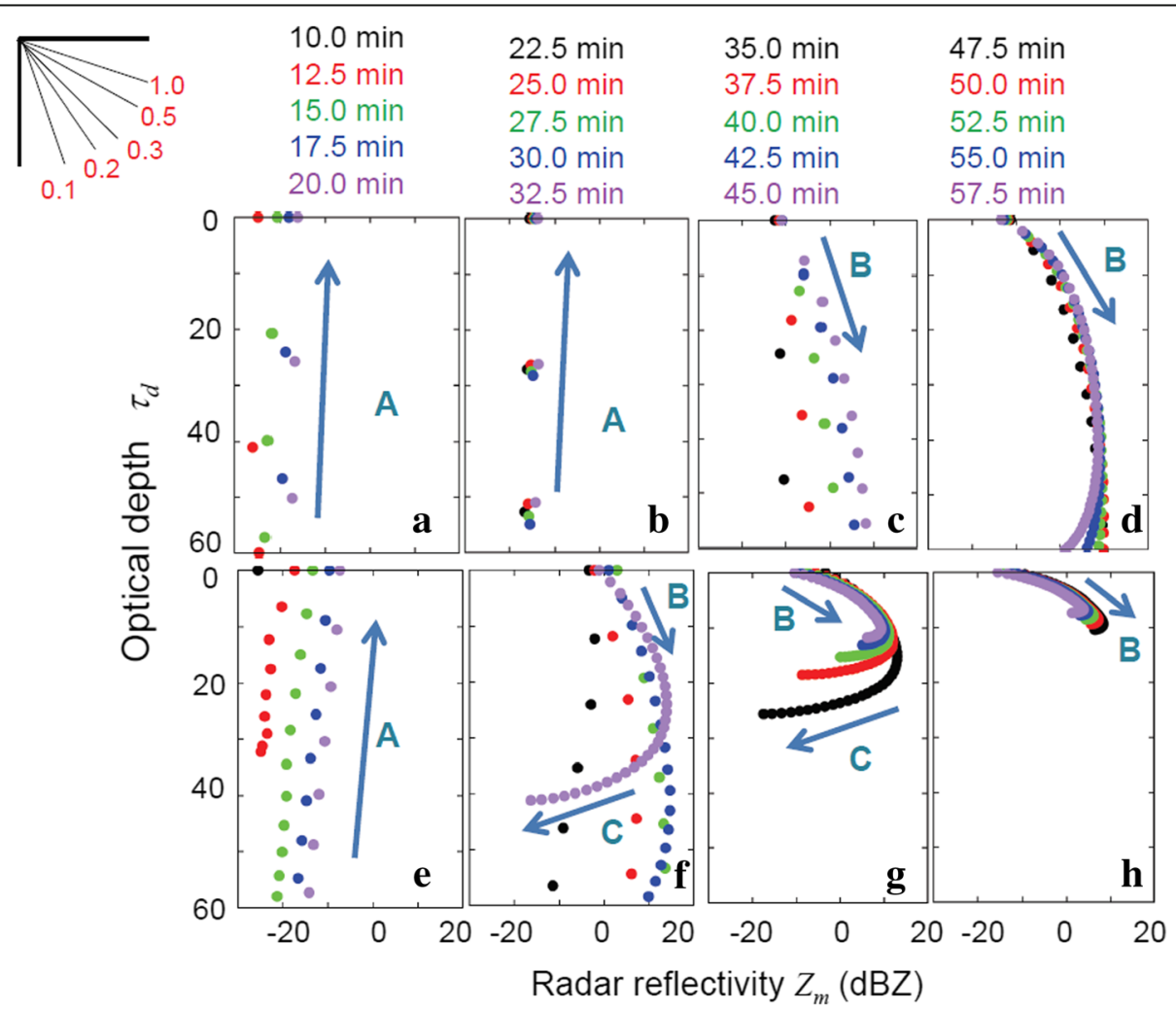

Fig. 4 Relationships between horizontally averaged radar reflectivity $Z_{m}$ and optical depth from cloud top, $\tau_{d}$, for cloud condensation nuclei with weak updraft. a-d Continental cloud condensation nuclei. $\mathbf{e}-\mathbf{h}$ Maritime cloud condensation nuclei. Arrays A, B, and C indicate the first, second, and third path, respectively (refer to the text). The diagram in the upper left shows the slope factor defined in Suzuki et al. (2010). Adapted from Fig. 5 of Kuba et al. (2015) 
shown by Suzuki et al. (2010b) and Sato et al. (2012) and suggest that the methodology using the kinematic driver is useful for studying cloud microphysical processes.

Kuba et al. (2018, personal communication) further compare different cloud microphysics schemes and propose a method for improving cloud microphysics schemes. They compared NDW6 with the KF-bin scheme using the two-dimensional kinematic driver model and a forward simulator of satellite measurements, following the approach by Kuba et al. (2014, 2015). They found that accumulated surface rainfall amounts are relatively similar but that the vertical distributions of rain-water mass are different. They determined that this difference is caused by overestimations of falling velocity of raindrops in NDW6. They also found that the slope factor of the relationships between $Z_{m}$ and $\tau_{d}$ near the cloud top in a later stage of cloud lifetime is smaller in NDW6 than in the KF-bin scheme, which is also caused by the overestimation of raindrop falling velocity in NDW6. Furthermore, Kuba et al. (2018, personal communication) found that suitable choices for a shape parameter, $v_{n}$ of a gamma distribution assumed as raindrop size distribution in NDW6 can improve the estimation of raindrop falling velocity. Observational data on raindrop number at ground level and from satellites can be used to adjust $v_{r}$ in NDW6 if the data can be classified by the environmental conditions of clouds.

\section{Cloud and circulation changes}

\section{Climate projection simulations by NICAM}

Climate projection simulations using NICAM have been conducted in a time slice approach by focusing on the changes in clouds and circulation systems, such as tropical and extra-tropical cyclones, between two different climates. That is, a set of experiments are conducted under the current climate condition and under the future climate condition by using the specified sea surface temperature (SST) of the respective situations, rather than an atmosphere-ocean coupled model. To be precise, the recent Atmospheric Model Intercomparison Project (AMIP) type and future climate experiments using NICAM by Kodama et al. (2015) and Yamada et al. (2017) were conducted with a slab ocean model nudged toward the specified SST.

In earlier attempts, Miura et al. (2005) examined simulated cloud changes by comparing an aqua planet experiment under a control condition with that under a warmer condition with SST uniformly increased by $4 \mathrm{~K}$. Their projected cloud changes were the first result from a global non-hydrostatic model with cloud microphysics schemes and without cumulus parameterization. The projected changes were found to be very different from those obtained by coarser-resolution GCMs with cumulus parameterization. Around the same time, Wyant et al. (2006) simulated a cloud response using a GCM with super parameterization (superparameterized Community Atmosphere Model; SP-CAM). Wyant et al. (2006) compared their result with the NICAM results of Miura et al. (2005) and found similarities and differences between the two models. In the high latitudes poleward of $50^{\circ}$, both models have strong cloud fraction increases despite their different surface boundary conditions. In the subtropics and tropics, the models showed opposite response of clouds: SP-CAM cloud fraction increased in the Intertropical Convergence Zone (ITCZ), while the NICAM cloud fraction decreased in the ITCZ. Such differences in cloud feedback in low latitudes by high-resolution models are reviewed by Bretherton (2015).

Collins and Satoh (2009), Satoh et al. (2012), and Tsushima et al. (2014) further analyzed a series of the perpetual July experiments between the control and the warming conditions based on the NICAM simulation results by Iga et al. (2007, 2011). In the tropical to sub-tropical area, they all showed that upper clouds increase as climate becomes warmer but ice water path (IWP) decreases. Such cloud responses are different from other GCMs (Tsushima et al. 2014), and the difference have been found to be robust. Satoh et al. (2012) examined the reason for the decrease in IWP and argued that the future weakening of circulation leads to a reduction of the ice production rate. This mechanism was recently used by Bony et al. (2016) to explain the "shrinking" of tropical upper clouds simulated by their GCMs. However, as described above, the NICAM results show an increase in upper clouds, so more detailed discussions are required to resolve this contradiction.

Chen et al. (2016) conducted similar experiment as Collins and Satoh (2009), Satoh et al. (2012), and Tsushima et al. (2014), but used two different cloud microphysics schemes: NSW6 and NDW6. The results of high-cloud changes and IWP were very similar in the two schemes, suggesting that these responses are robust, at least when using NICAM.

These studies raise the question of why such high-cloud responses occur and why the high-cloud responses of NICAM are different from those of the other GCMs. Noda et al. (2014) partly answered the latter question by analyzing the areal size distribution and radiative effects of high clouds. Changes in cloud clusters are a main focus of the NICAM subgroup of the SOUSEI program. Because cloud distributions simulated by NICAM look similar to those observed in satellite images (Miura et al. 2007), the area coverage of high clouds is analyzed and compared with observations (Inoue et al. 2008). Using this method, Noda et al. (2014) compared 
the distribution of cloud size in the two climates and found that the number of smaller high clouds is more drastically increased in the warmer climate and that the cloud radiative forcing by smaller clouds less than about $50 \mathrm{~km}$ in radius contributed to the positive feedback by LWCRF. Such small-scale clouds are not generally explicitly represented by ordinary GCMs and parameterized by cloud macro-physics schemes such as cloud fraction, but they are explicitly represented in NICAM. These findings suggest that assumptions introduced in the cloud macro-physics schemes should be examined more closely and compared with explicit calculations using cloud microphysics schemes to understand the different responses of high clouds between models. Noda et al. (2016) extended this approach to examine the fixed anvil temperature (FAT) hypothesis (Hartmann and Larson 2002) as described below.

Projected changes in circulation systems are also examined using NICAM simulations. Since deep convective circulations are explicitly represented by NICAM, future changes in cloud systems can be examined together with changes in meso-scale properties and their embedding synoptic structures. TC changes were examined by Yamada et al. (2010), who used NICAM to show decreases in the number of TCs and more frequent intensive cyclones, consistent with other GCMs (Knutson et al. 2010). They further examined the eye wall structures and showed that eye wall height tends to increase with TC intensity. Yamada and Satoh (2013) examined projected changes in ice and liquid clouds associated with TCs. These studies are based on the results of 5-month simulations, which are too short to explore basin-scale differences or inter-annual variabilities. Recently, however, Yamada et al. (2017) used the K computer to extend these experiments to a multi-decadal time scale: the AMIP-type experiment under the present-day climate condition and the corresponding experiment under the future climate condition (Kodama et al. 2015; Satoh et al. 2017). Yamada et al. (2017) showed basin-scale changes in TCs and seasonal variations. In general, the global TC statistics from the NICAM simulations were consistent with those reported by Knutson et al. (2010). Yamada et al. (2017) further analyzed the structural changes in TCs and showed that the horizontal scale of TCs increased with warming when compared between TCs of the same categories in the two climates. Using these simulation results, Satoh et al. (2015) analyzed convective mass flux associated with TCs and proposed a constraint for a future decrease in the number of TCs.

Future changes in extra-tropical cyclones are examined by Kodama et al. (2014) using the aqua planet experiments conducted by Yoshizaki et al. (2012). Their simulation shows that, similar to the TC response, the frequency of extra-tropical cyclones decreased but the cyclones slightly intensified on average. The storm track moved poleward, consistent with other GCMs.

In the subsequent subsections, we review the outcomes of the SOUSEI program, the analysis of cloud size statistics, upper cloud changes, and extra-tropical cyclone changes in more detail.

\section{Changes in the size distribution of high clouds}

As reviewed in the previous section, increased high-cloud coverage is consistently observed in NICAM simulations (Collins and Satoh 2009; Satoh et al. 2012; Tsushima et al. 2014; Chen et al. 2016). To explore the characteristic change in high clouds, we show the size distribution of high cloud in Fig. 5, along with satellite data. Here, we show additional cloud size analysis of the 1 -year present-day control simulations and global warming simulations at mesh size of $7 \mathrm{~km}$ and $14 \mathrm{~km}$ used by Noda et al. (2016). We defined a high-cloud region as one where the modeled OLR was less than $210 \mathrm{~W} \mathrm{~m}^{-2}$. Cloud sizes are shown as an equivalent radius of a circle, and thus, the minimum radius is approximately half of the model grid size (Noda et al. 2012, 2014).

The NICAM result shows good agreement with the satellite data except for clouds with a radius smaller than $30 \mathrm{~km}$, which show negative bias in the frequency. However, this bias is improved by reducing the grid size from 14 to $7 \mathrm{~km}$, consistent with Inoue et al. (2008). Under the warmer condition, the number of clouds increases in all radius bins. In particular, smaller clouds increase in frequency more than larger clouds. The smaller clouds contribute more to the increase in the total high-cloud coverage under the warmer condition.

Changes in OLR due to changes in high clouds directly affect projected changes to the global radiative budget. We define a diagnostic equation for the changes in OLR which decomposes relative contributions of various cloud properties: cloud emissivity $(\varepsilon)$, cloud-top temperature $\left(T_{\mathrm{CT}}\right)$, and clear-sky OLR $\left(F^{\mathrm{CLR}}\right)$. The response of OLR, $F$, to global warming $\Delta$, can be approximated as.

$$
\begin{aligned}
& \Delta \bar{F}^{(i)} \cong\left(\frac{\partial F}{\partial \varepsilon}\right)_{T_{\mathrm{CT}}, F^{\mathrm{CLR}}} \Delta \bar{\varepsilon}^{(i)}+\left(\frac{\partial F}{\partial T_{\mathrm{TC}}}\right)_{\varepsilon, F^{\mathrm{CLR}}} \Delta \overline{T_{\mathrm{CT}}}(i) \\
&+\left(\frac{\partial F}{\partial F^{\mathrm{CLR}}}\right)_{\varepsilon, T_{\mathrm{CT}}} \Delta \overline{F^{\mathrm{CLR}}}\left({ }^{(i)}\right. \\
& \equiv F_{\varepsilon} \Delta \bar{\varepsilon}^{(i)}+F_{T} \Delta{\overline{T_{\mathrm{CT}}}}^{(i)}+F_{F} \Delta{\overline{F^{\mathrm{CLR}}}}^{(i)}
\end{aligned}
$$

where

$$
F_{\varepsilon}=\sigma\left({\overline{T_{\mathrm{CT}}}}^{(i)}\right)^{4}-{\overline{F^{\mathrm{CLR}}}}^{(i)},
$$


$\mathbf{a}$

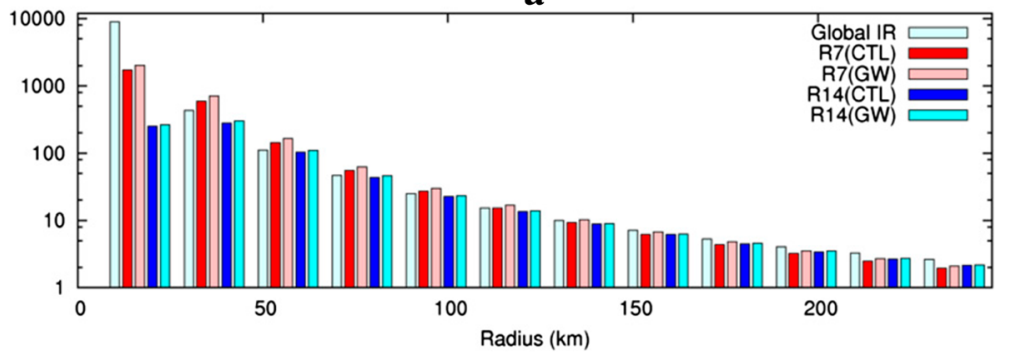

b

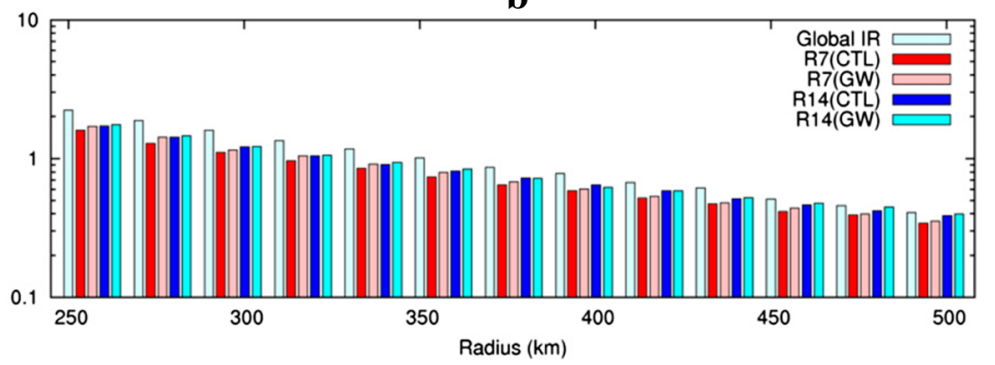

Fig. 5 Frequency distribution of high-cloud size. The radius of high clouds is derived from global infrared data (Global IR) and from present-day control simulations (CTL) and global warming simulations (GW) at mesh resolutions of $7 \mathrm{~km}$ (R7) and $14 \mathrm{~km}$ (R14). Cloud size (radius) is binned every $20 \mathrm{~km}$. The top panel a shows for the size range between 0 and $250 \mathrm{~km}$, while the bottom panel $\mathbf{b}$ shows the size range between 250 and $500 \mathrm{~km}$. Adapted from Noda et al. (2014a)

$$
\begin{aligned}
& F_{T}=4 \bar{\varepsilon}^{(i)} \sigma\left({\overline{T_{C T}}}^{(i)}\right)^{3}, \\
& F_{F}=1-\bar{\varepsilon}^{(i)} .
\end{aligned}
$$

An overbar with a prefix $i$ denotes an average over $i$ th cloud area. Those values are hereafter shown by being binned according to the cloud radius. Using the above formulae, one can evaluate the contributions of $\varepsilon, T_{\mathrm{CT}}$, and $F^{\mathrm{CLR}}$ to changes in $F$.

Figure 6 shows the contribution of each term of (1); the vertical axis is the accumulated contribution of the cloud size whose radius is less than the value in the horizontal axis. The contribution of each term clearly differs depending on cloud size; the change in $T_{\mathrm{CT}}$ contributes more to clouds smaller than $400 \mathrm{~km}$ in radius. In contrast, changes in both $T_{\mathrm{CT}}$ and $\varepsilon$ contribute almost equally to clouds larger than $400 \mathrm{~km}$. The contribution of the change in $F^{\mathrm{CLR}}$ is minor relative to the other two elements, and it acts to reduce OLR. The contribution of $\varepsilon$ increases rapidly for clouds up to $300 \mathrm{~km}$ in radius, followed by an almost linear increase, and then asymptotically approaches a constant value (Fig. 6b). In contrast, the contribution of $T_{\mathrm{CT}}$ increases almost linearly, independent of cloud size, and eventually approaches a constant value. The net contributions of the two elements are comparable. The contribution of $F^{\mathrm{CLR}}$ is one order smaller than that of the other elements.

Hartmann and Larson (2002) claimed that $T_{\mathrm{CT}}$ is kept almost constant, irrespective of surface temperature, which is referred to as the FAT hypothesis. Our analysis reveals that the FAT hypothesis is valid for smaller high clouds for which the contribution of $T_{\mathrm{CT}}$ change is smaller than that of $\varepsilon$ change. However, the validity of the hypothesis can be uncertain for larger clouds because changes to both $T_{\mathrm{CT}}$ and $\varepsilon$ contribute almost equally to OLR change; the former contribution is not negligible. In other words, whether the FAT hypothesis holds or not depends on which size of cloud primarily increases or decreases due to global warming. This suggests that the size distribution of high clouds should be examined for more reliable projections of radiation budget.

\section{High cloud changes in two different microphysics scheme experiments}

Clouds play an important role in the uncertainty of the climate projection under the global warming condition because of their influence on the energy balance of the atmosphere (Hartmann et al. 1992). The uncertainty of GCM-simulated climate projection comes from the large spread in cloud responses to global warming as found in CMIP3 and CMIP5 (Vial et al. 2013). In particular, we focus on cloud ice simulations (Waliser et al. 2009; Li et al. 2013).

Chen et al. (2016) examined how cloud responce changes by using NICAM with two cloud microphysics schemes, NSW6 and NDW6, and compared these results with those of the GCM simulations from CMIP3 and CMIP5. The aim of their study was to reveal 

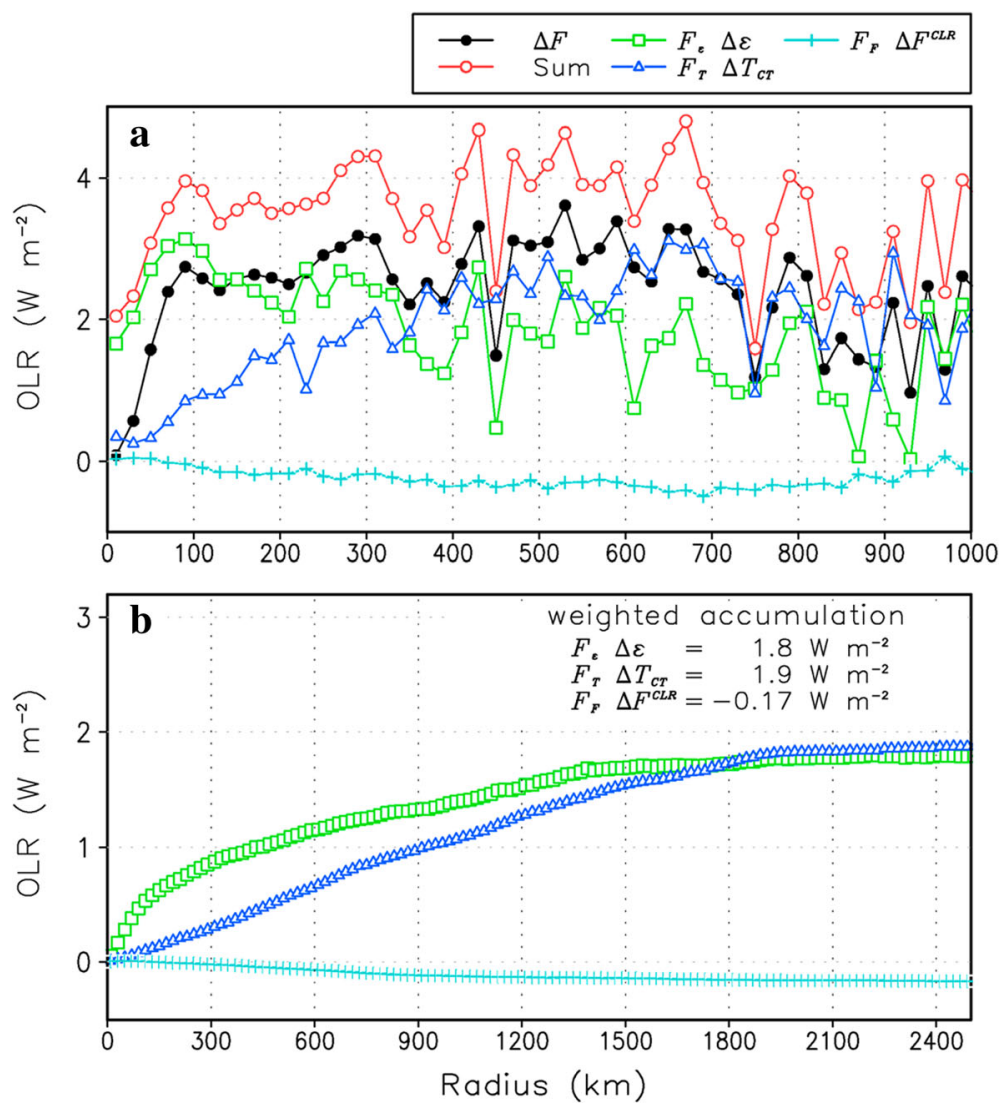

Fig. 6 Budget analysis of outgoing longwave radiation changes due to global warming. Cloud size is binned by radius (20 km bins), showing a mean values of outgoing longwave radiation (OLR) for each cloud size and $\mathbf{b}$ the OLR area-ratio-and-frequency-of-occurrence-weighted accumulation in the $x$ (radius) direction (i.e., $\sum_{i r=1}^{\infty} \varphi_{i r} \frac{\pi r_{i r}^{2}}{S} P_{i r}$, where $S=\sum_{i r=1}^{\infty} \pi r_{i r}^{2}, \varphi_{i r}$ and $r_{i r}$ denote values of each term shown in $\mathbf{a}$ and cloud radius at the irth bin, respectively. $P$ denotes the probability distribution function of high cloud number). The original OLR values (black), diagnosed values from Eq. (2) (red), and the contributions of each term on the right hind side of Eq. (2) (green, blue, and cyan) are plotted. Adapted from Noda et al. (2016)

whether the responses of clouds, particularly high clouds, to global warming in NICAM simulations are robust irrespective of the choice of cloud microphysics schemes. Chen et al. (2016) further calculated the cloud radiative feedback of the results from NSW6 and NDW6 using the cloud radiative kernel proposed by Zelinka et al. (2012). Because the available integration time was limited to 1 year for NSW6 and to the boreal summer experiment from June to August for NDW6, Chen et al. (2016) focused on the longwave (LW) cloud feedback, which exhibit a smaller seasonal dependency compared with SW cloud feedback. The 1-year experiment with NSW6 is referred to as NSW6-ANNUAL, the boreal summer experiment with NSW6 as NSW6-JJA, and the experiment with NDW6 as NDW6-JJA.

Figure 7 plots the global mean SW, LW, and net cloud radiative feedback corresponding to all clouds and each type of clouds, with clouds classified by cloud top pressure (CTP) and cloud optical depths (COD). The results from CMIP5 and the Cloud Feedback Model Intercomparison Project Phase 2 (CFMIP2 ${ }^{4}$ ) for each model and their average are also plotted for comparison. The comparison between NSW6-ANNUAL and NSW6-JJA indicates that the seasonal variation in the net cloud feedback comes mainly from the seasonal variation in the SW cloud feedback and that the LW cloud feedback are almost stable irrespective of season. The differences in the LW cloud feedback between NSW6-JJA and NDW6-JJA are then examined; the total LW cloud feedback and those of almost all the cloud categories for both NSW6 and NDW6 are within the uncertainty of the CMIP5/CFMIP2 model ensemble (Fig. 7). However, there is an exception; the LW cloud feedback attributed to the thin-cloud response to global warming are considerably larger than those in the CMIP5/CFMIP2 model ensembles.

Figure 8 decomposes the LW cloud feedback shown in Fig. 7 into each cloud category for NSW6-JJA (Fig. 8a) and NDW6-JJA (Fig. 8b). The results demonstrate that the large positive LW cloud feedback are attributed mostly to cirrus clouds (high and thin clouds) in both NSW6-JJA and NDW6-JJA. This large cirrus cloud 
Feedback: NSW6, NDW6, and CMIP5/CFMIP2

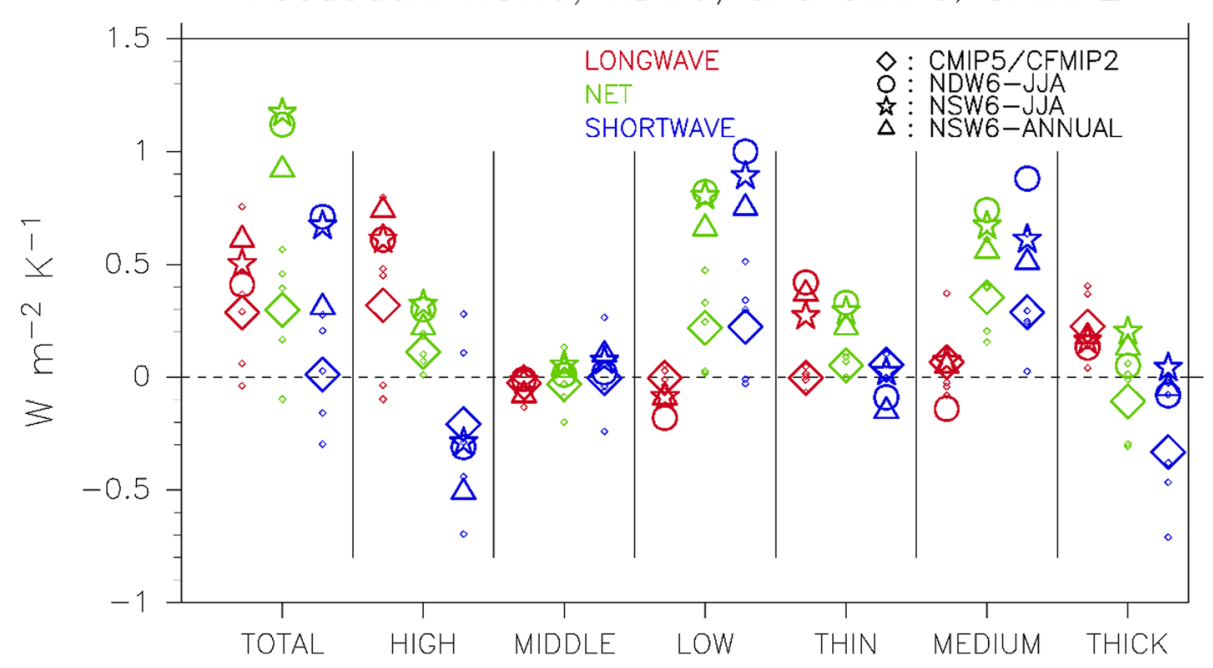

Fig. 7 The global mean cloud feedback. Clouds are classified by cloud top pressure (CTP) and cloud optical depth (COD): high clouds, CTP $\leq$ $440 \mathrm{hPa}$; middle clouds, $440 \mathrm{hPa} \leq \mathrm{CTP}<680 \mathrm{hPa}$; low clouds, $680 \mathrm{hPa} \leq \mathrm{CTP}<1000 \mathrm{hPa}$; thin clouds, $0.3 \leq \mathrm{COD}<3.6$; medium clouds, $3.6 \leq \mathrm{COD}$ $<23$; thick clouds, $23 \leq$ COD). Longwave, shortwave, and net cloud feedback are shown in red, blue, and green, respectively, for NSW6-ANNUAL (triangles), NSW6-JJA (stars), NDW6-JJA (circles), and CMIP5/CFMIP2 average (diamonds). The small dots indicate each member of the CMIP5/ CFMIP2 models (courtesy of Dr. Mark Zelinka). Adapted from Chen et al. (2016)

contribution to the LW cloud feedback is dominated by clouds with CTP $<180 \mathrm{hPa}$ for both NSW6-JJA and NDW6-JJA. For NSW6-JJA, clouds with CTP $<180 \mathrm{hPa}$ and COD $<3.6$ contribute to the positive LW cloud feedback, whereas clouds with CTP $>180 \mathrm{hPa}$ contribute to negative LW cloud feedback. For NDW6-JJA, among high clouds, clouds with $\mathrm{CTP}<310 \mathrm{hPa}$ contribute to positive LW cloud feedback, whereas LW cloud feedback of clouds with $\mathrm{CTP}<180 \mathrm{hPa}$ and $1.3<\mathrm{COD}<3.6$ are slightly negative. This difference is consistent with the difference in cloud fraction response to global warming (not shown).

Figure 9 shows the zonal mean distributions of cirrus cloud (high and thin cloud) change and the LW cloud feedback attributed to cirrus cloud changes for NSW6-JJA (Fig. 9a) and NDW6-JJA (Fig. 9b). For NSW6-JJA, the cirrus cloud fraction significantly increases in the tropics and, as a result, the LW cloud feedback attributed to cirrus clouds are mostly dominant in the tropics. In contrast, although the NDW6-JJA cirrus cloud fraction changes mainly in the tropics, appreciable changes occur in the mid-latitudes. This means that the LW cloud feedback from cirrus clouds dominate in the tropics, although they are non-negligible in the mid-latitudes.

As described above, Chen et al. (2016) indicated that projected changes of high clouds simulated by NICAM with the two different cloud microphysics schemes show similar increases in high and thin clouds over the tropics and the subtropics. Chen et al. (2016) further analyzed the difference between the two schemes and found that the change in the effective radius of ice particles has a non-negligible impact on LWCRF in NDW6 through emissivity of clouds. This result demonstrates the importance of ice cloud microphysics in making more accurate assessments of cloud radiative forcing.

\section{Clouds, precipitation, and storm changes in the multi- decadal experiments}

As introduced earlier in this review, a long-term multi-decadal simulation using NICAM with a horizontal $14 \mathrm{~km}$ mesh has been achieved (Kodama et al. 2015; Satoh et al. 2015, 2017; Yamada et al. 2017). The NICAM $14 \mathrm{~km}$ AMIP-type simulations were performed for the present climate of 1979-2008 and the future climate of 2074-2100. The present simulation was analyzed by Kodama et al. (2015) and Satoh et al. (2017), while Satoh et al. (2015) and Yamada et al. (2017) discussed projection of TCs using the present and the future simulations. Kodama et al. (2015) and Satoh et al. (2015) only used the first 20 years simulation from June 1979 to May 1998, because of the simulation was not finished at the time these papers were published. In this and the next subsections, we review future changes in cloud and precipitation and associated circulation changes, such as TCs and storm tracks, due to global warming using outputs of long-term NICAM simulations.

NSW6 was utilized to explicitly calculate cloud microphysics without a cumulus parameterization scheme. The atmospheric radiation transfer scheme MSTRNX (Sekiguchi and Nakajima 2008), a second-order 

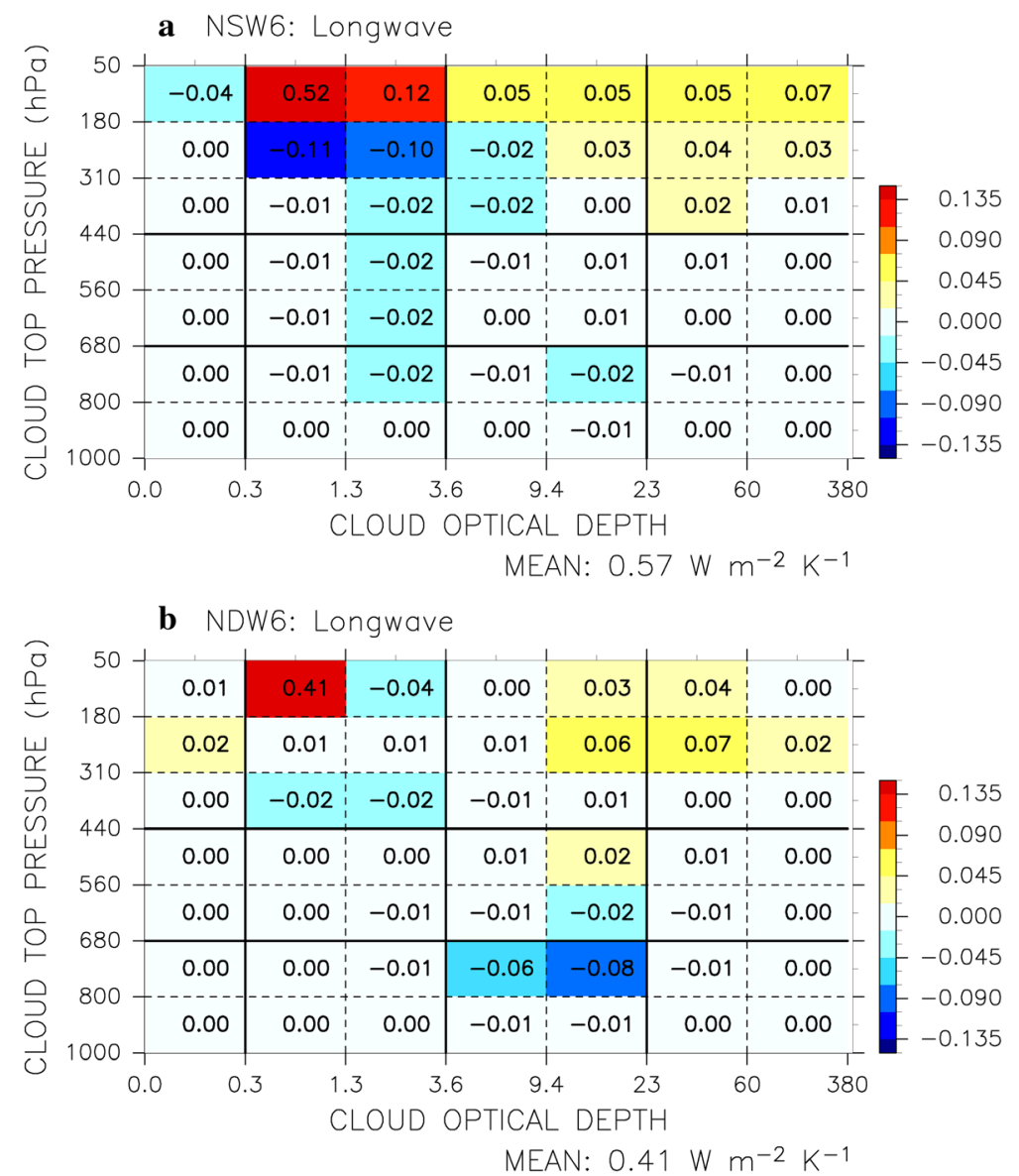

Fig. 8 Longwave cloud feedback [W $\mathrm{m}^{-2} \mathrm{~K}^{-1}$ ] on International Satellite Cloud Climatology Project (ISCCP) diagrams estimated from the cloud radiative kernel. Longwave cloud feedback in a NSW6-JJA and $\mathbf{b}$ NDW6-JJA are plotted in the ISCCP diagram with cloud top pressure (vertical axis) and cloud optical depth (lateral axis). Adapted from Chen et al. (2016)

turbulence closure scheme (Nakanishi and Niino 2006; Noda et al. 2010) and the land surface model MATSIRO (Takata et al. 2003) have been used. A slab ocean model was utilized to simulate SSTs, which were nudged toward Taylor-corrected (Taylor et al. 2000) HadISST1 values in the present-day climate simulation. In the future climate simulation, the simulated SSTs were nudged toward future SSTs, which were estimated by adding the SST differences between the present-day (1979-2003) and future (2075-2099) climate periods to the HadISST1 values. The SST differences were obtained from outputs of the CMIP3 dataset of the World Climate Research Program (WCRP) (Mizuta et al. 2008).

Figure 10 shows the climatological daytime cloud amount and its future change for high, middle, and low clouds. The cloud amount was estimated using the International Satellite Cloud Climatology Project (ISCCP) simulator (Klein and Jakob 1999; Webb et al. 2001). The high-cloud amount is increased, as shown by the upper panels of Fig. 10, consistent with the results of previous studies using NICAM (Satoh et al. 2012; Chen et al. 2016). The low-cloud amount is decreased between $60^{\circ} \mathrm{S}$ and $60^{\circ} \mathrm{N}$, which is prominent near the west coast of continents, and is increased at high latitudes (polar side of about $60^{\circ} \mathrm{S}$ and $60^{\circ} \mathrm{N}$ ). The decrease in the low-cloud amount is also related to an increase in cloud-top height due to warming SST. The reduction of the low-cloud amount is similarly seen in many conventional GCMs (Zelinka et al. 2013, 2016, 2017).

Figure 11 shows the seasonal climatological means of the simulated precipitation rate and its future change during June-July-August (JJA), September-OctoberNovember (SON), December-January-February (DJF), and March-April-May (MAM). Under the future climate condition, the global averaged precipitation rate increased by approximately $1.0 \mathrm{~mm} \mathrm{day}{ }^{-1}$ for all seasons. The distribution of zonal mean precipitation rates is shown in the right panels of Fig. 11. The model projects that the precipitation rate is increased in the tropics, slightly decreased over the subtropics, and increased at the higher latitudes. An increase is prominent near ITCZ throughout all seasons. Clear decreases are seen over the 

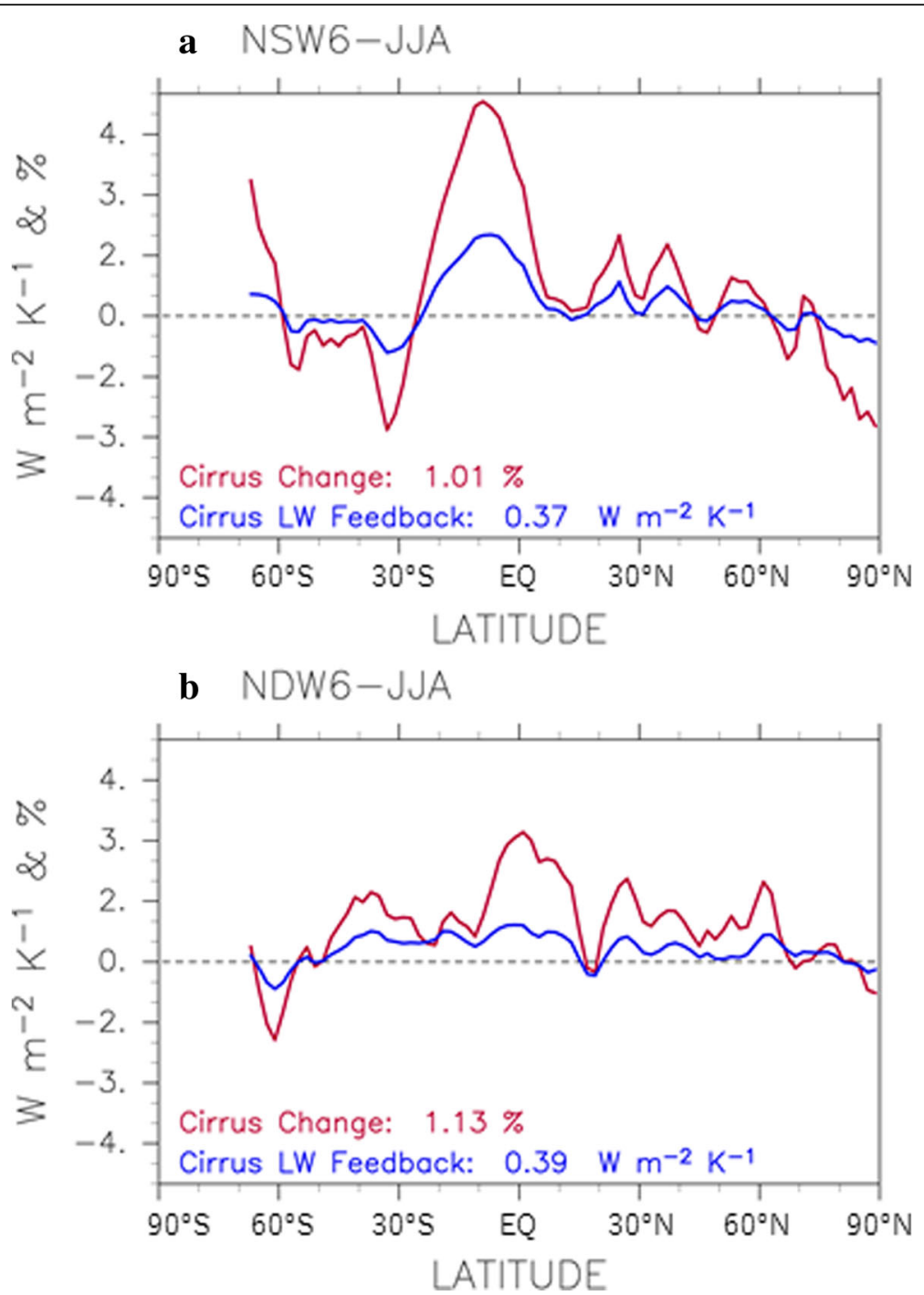

Fig. 9 The zonal mean distribution of cloud changes. Cirrus cloud changes (red lines) and longwave cloud feedback contributed by cirrus clouds changes (blue lines) are shown for a NSW6-JJA and $\mathbf{b}$ NDW6-JJA. Note that the longwave cloud radiative feedback are calculated using the cloud radiative kernel proposed by Zelinka et al. (2012). Adapted from Chen et al. (2016)

subtropical eastern North Pacific during JJA, and the tropical Indian Ocean during JJA and SON.

The change in TC activities is documented in Satoh et al. (2015) and Yamada et al. (2017). Precipitation related to TCs has been investigated in previous studies (Rodgers et al. 2000; Scoccimarro et al. 2014), which used an observational dataset to show that TCs contributed considerably to rainfall over the subtropical eastern North Pacific, where the contribution was more than $40 \%$ at maximum. Figure 12 shows the contributions of rainfall associated with TCs to the total rainfall in the present-day and future climate simulations for JJA, SON, DJF, and MAM. Here, rainfall associated with TCs is defined as rainfall within $500 \mathrm{~km}$ from the center of the TC (hereafter, referred to as TC-rainfall). The TC-rainfall rate is high over the subtropics during all seasons in both climate conditions (right panels of Fig. 12). In the present-day climate simulation, the contribution of TC-rainfall to total rainfall is more than 60\% during JJA and SON over the subtropical eastern North Pacific, where TCs are frequently generated during these seasons. This result is qualitatively consistent with observational studies (Rodgers et al. 2000; Scoccimarro et al. 2014). Under the future climate condition, the TC-rainfall rate during JJA is decreased over the subtropical eastern North Pacific (center panels of Fig. 12), where the total precipitation rate is also decreased (center panels of Fig. 11). Therefore, future change in TCs appears to contribute to the decrease in precipitation over the subtropical eastern North Pacific in the future climate simulation. 


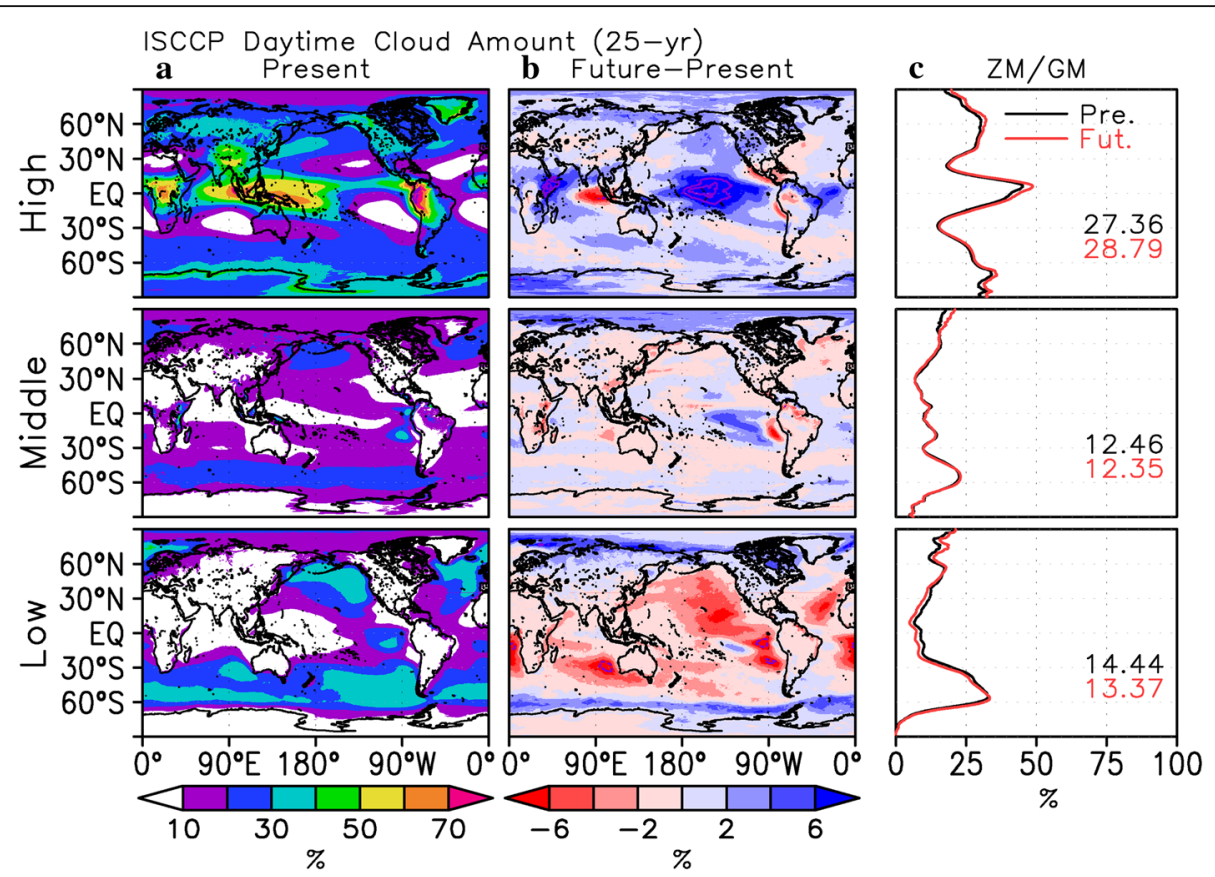

Fig. 10 Annual mean International Satellite Cloud Climatology Project (ISCCP) daytime cloud amount (\%). Panels represent high, middle, and low clouds from top to bottom. a Results of the present-day climate simulation (1979-2003) with ISCCP simulator. b Differences between the future climate (2075-2099) and present-day climate simulations with ISCCP simulator. c The zonal mean (ZM) and global mean (GM) values for the present-day climate simulation (black) and the future climate simulation (red). Adapted from Chen et al. (2016)

\section{Storm track and its cloud radiative effect}

It is still unclear how clouds interact with large-scale circulation in the extratropics. Many studies using GCMs project a poleward shift of the storm track, a reduction in the total number of extratropical cyclones, and an increase in the number of intense extratropical cyclones due to global warming (Geng and Sugi 2003; Yin 2005; Mizuta 2012). Most GCMs also project a negative cloud feedback by SW radiation in the higher latitudes (Zelinka et al. 2012) in association with an increase in liquid water optical depth (Ceppi et al. 2015; Bodas-Salcedo et al. 2016). It has also been suggested that enhanced extratropical cyclone intensities due to global warming induce more SW cooling and more LW warming (Tselioudis and Rossow 2006). In contrast, a poleward shift of the storm track does not seem to induce a significant positive SW cloud radiative effect in the southern hemisphere (Grise and Polvani 2014). These previous studies employed conventional GCMs with a mesh size of $\mathrm{O}\left(10^{2} \mathrm{~km}\right)$. Much higher horizontal resolution is necessary to reproduce fine-scale structures of extratropical cyclones such as cold and warm fronts.

Bengtsson et al. (2009) and Champion et al. (2011) used global models with 40-60 km horizontal resolutions and projected an increase in precipitation around extratropical cyclones due to global warming. They also suggested a need for non-hydrostatic model simulations with finer horizontal resolution to study the responses of precipitation and wind fields. Miura et al. (2005) analyzed a set of short-term aqua planet experiments and found that high-latitude total cloud amount responded differently to an increase in SST between $7 \mathrm{~km}$ mesh NICAM and T42 $\left(2.8^{\circ}\right)$ GCM. Kodama et al. (2014) further analyzed the output of aqua planet experiments using $14 \mathrm{~km}$ mesh NICAM and showed an increase in liquid water optical depth and enhancement of SW cooling, consistent with the GCM results.

In this subsection, we show additional analysis of the cloud radiative effect in the extratropics using the output data of the present-day and future climate simulations described in the previous subsections. We focus on the southern hemisphere for simplicity. Mean sea level pressure, temperature, and wind fields from the JRA-55 reanalysis dataset (Kobayashi et al. 2015; Harada et al. 2016) and cloud radiative effect from CERES SYN1deg computed product (Loeb et al. 2009) are used to evaluate the performance of the present-day climate simulation.

We detected and tracked extratropical cyclones in the reanalysis and simulations based on the mean sea level pressure. The mean structure of a field variable around extratropical cyclones was diagnosed by compositing it against cyclone centers following the methodology described by Kodama et al. (2014) with slight modifications. In addition, the relationship between the location of the mid-latitude low-level jet and the magnitude of 


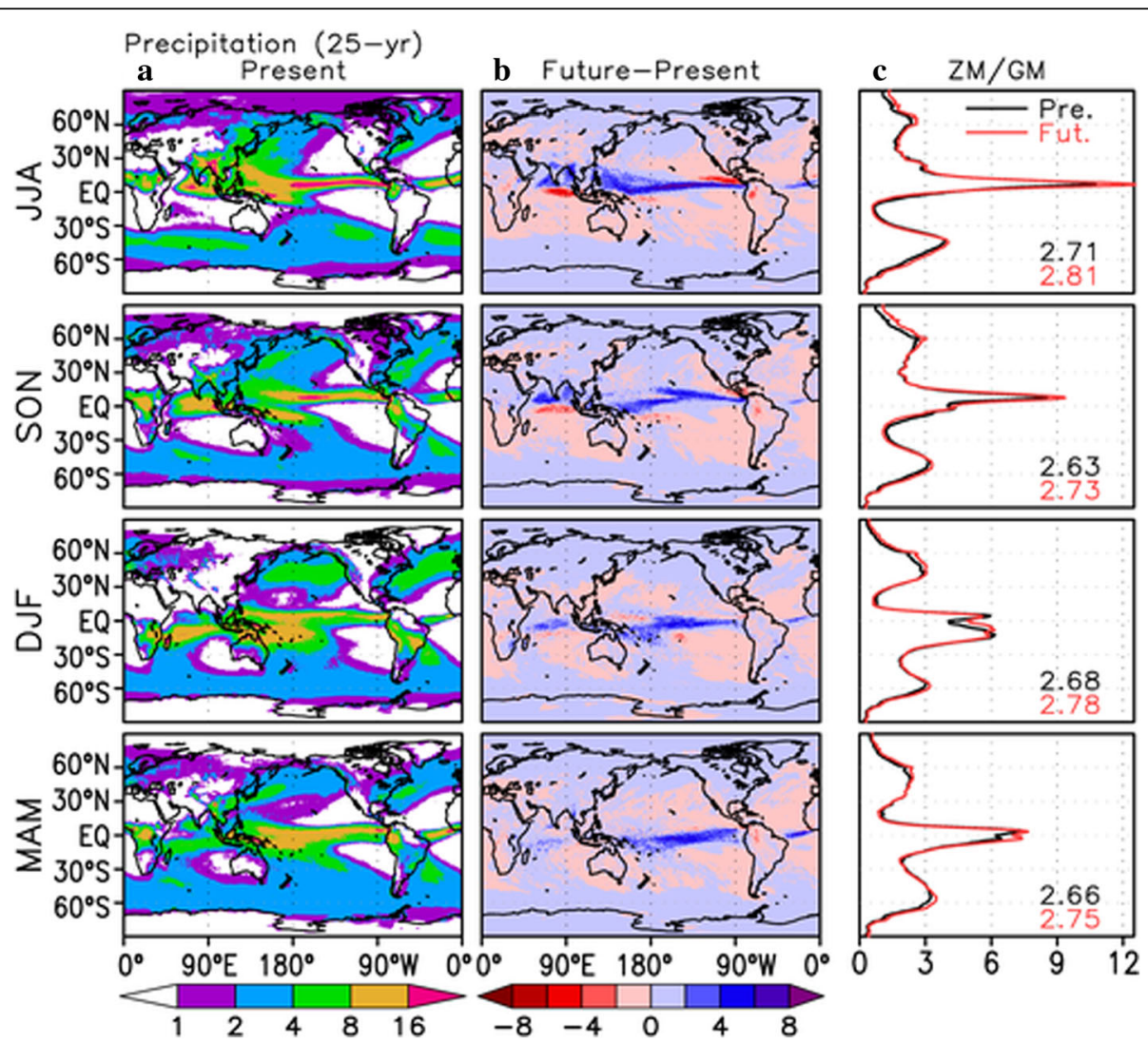

Fig. 11 Seasonal mean climatological precipitation rates $\left(\mathrm{mm}\right.$ day $\left.{ }^{-1}\right)$ throughout the year. Panels show June-July-August (JJA), September-October-November (SON), December-January-February (DJF), and March-April-May (MAM). a Results of the present-day climate simulation (1979-2003). b Differences between future climate (2075-2099) and the present-day climate simulation. c The zonal mean (ZM) and global mean (GM) values for the present-day climate simulation (black) and the future climate simulation (red)

the cloud radiative effect was analyzed following Grise and Polvani (2014). First, anomalies from monthly mean climatology were taken for LW and SW cloud radiative effects and peak latitude of the zonal mean zonal wind at $1500 \mathrm{~m}$ in altitude (hereafter, jet latitude). Then, regressions on the jet latitude were calculated to obtain changes in the LW and SW radiative effects by jet shift of $1^{\circ}$ in latitude.

Figure 13a, d shows the mean horizontal structures of the observed LW and SW cloud radiative effects around extratropical cyclones in the southern hemisphere. Net cloud radiative effect is negative as a result of a compensation between SW cooling and LW warming. A characteristic comma-like pattern is evident around the poleward and eastward sides of the cyclone center. Overall, results from the present-day climate simulation (Figs. 13b, e) capture the observed horizontal structure of the LW and SW cloud radiative effects around extratropical cyclones. The simulated LW cloud radiative effect agrees well with observation, with slightly warmer bias. The model underestimates SW cloud radiative cooling by roughly $10 \mathrm{~W} \mathrm{~m}^{-2}$ or more, which is consistent with an underestimation of the zonal mean low- and middle-level cloud fractions (Kodama et al. 2015).

Figure 13c, $\mathrm{f}$ shows the responses of LW and SW cloud radiative effects to global warming. SW cloud radiative cooling is enhanced in the entire extratropics and peaks near the cyclone center. LW cloud radiative warming is slightly increased around the poleward and eastward sides of the cyclone center. These changes in SW and LW cloud radiative effects resemble changes in the liquid and ice water paths, respectively (not shown), which are consistent with the results of the aqua planet experiments (Kodama et al. 2014). The magnitudes of the changes in SW and LW cloud radiative effects (scaled by changes in surface air temperature) are far greater in the aqua planet experiments than in this study.

Figure 14 shows changes in the LW and SW cloud radiative effects. This reflects effects of the $1^{\circ}$ poleward shift of the jet latitude. The simulated jet, on average, is located at $50^{\circ} \mathrm{S}$. As the jet shifts poleward, the anomaly of the LW cloud radiative effect becomes positive in the 

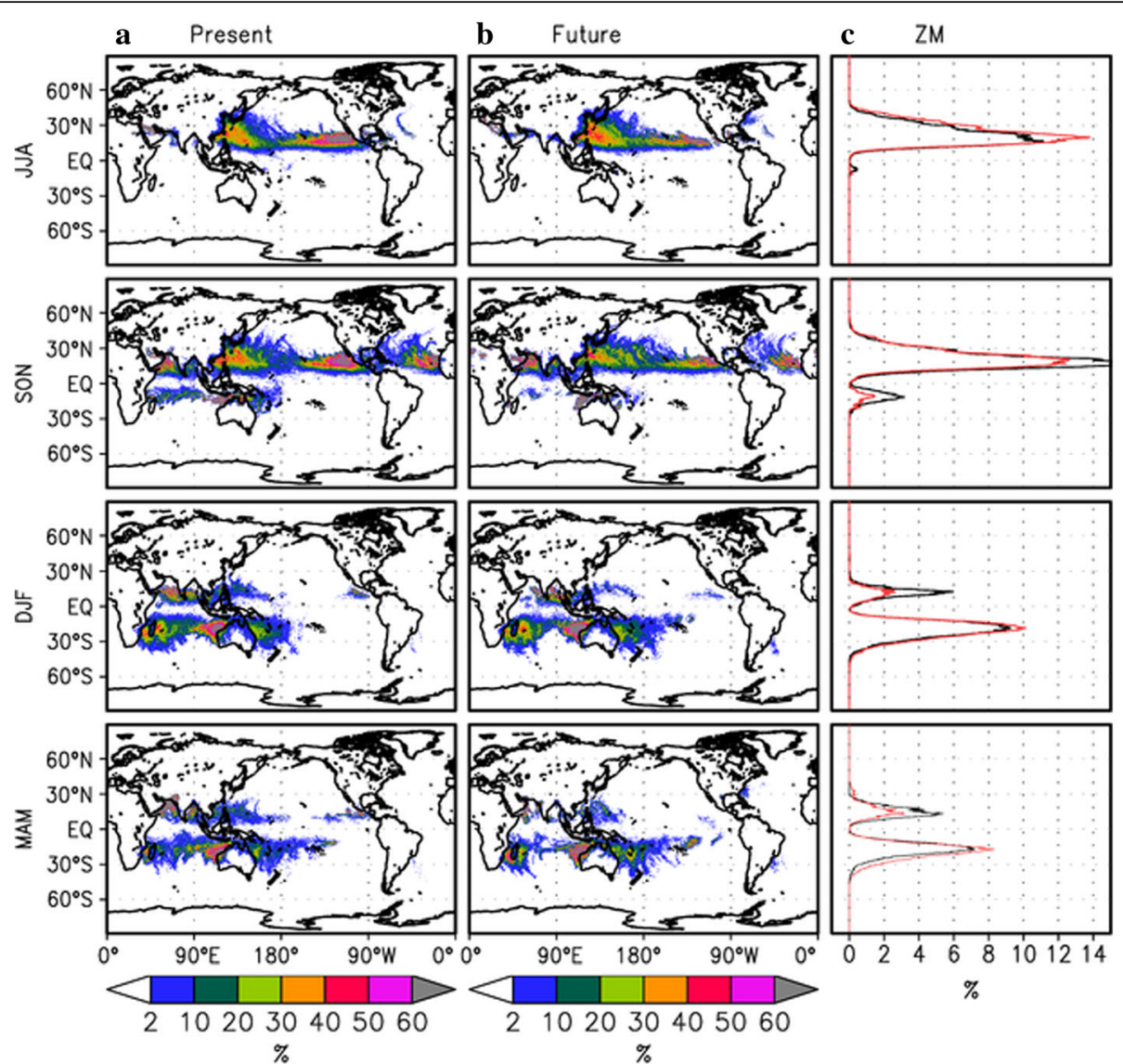

Fig. 12 Seasonal mean climatological contributions (\%) of rainfall associated with tropical cyclones to total rainfall. Results of the a present-day climate simulation (1979-2003) and $\mathbf{b}$ the future climate simulation (2075-2099). c The zonal mean (ZM) values for the present-day climate simulation (black) and for the future climate simulation (red). The rainfall associated with tropical cyclones is defined as rainfall within $500 \mathrm{~km}$ from the center of tropical cyclones. The panels follow the same seasons as defined in Fig. 11

poleward flank of the jet latitude and negative in the equator flank. The response of SW cloud radiative effects to the jet shift is small in the extratropics and negative in the subtropics. Grise and Polvani (2014) showed that, as the jet shifts poleward, half of the CMIP5 models (type I models in their study) reproduce the positive anomaly of SW cloud radiative effect induced by the poleward jet shift, whereas the other half (type II models) show no significant changes in SW cloud radiative effect. Analysis of the CERES product supports type II models (Grise and Polvani 2014). Our model is also consistent with the type II models, supporting the discovery that the position of the dynamic storm track does not influence the cloud radiative effect in the mid-latitudes.

\section{Discussion}

\section{Cloud feedback}

For the past decade, seasonal- to annual-scale simulations by NICAM have been used to investigate clouds, circulation, and climate sensitivity. Using outputs of
$14 \mathrm{~km}$ mesh present-day and future climate simulations by NICAM (Kodama et al. 2015), we estimated the cloud feedback by analyzing the dataset for the climate-scale output (Fig. 15). As a result, the cloud feedback parameters derived from the NICAM climate simulations (Fig. A2 in Chen et al. 2016; Fig. 15) are quantitatively similar to those from seasonal- to annual-scale simulations (Fig. 7). Specifically, positive LW radiative feedback from thin cloud (mainly cirrus) changes, which has been suggested to be different from other GCMs by Chen et al. (2016), is still found in NICAM climate simulations. In addition, low-level cloud is decreased more due to global warming compared with the CMIP3 and CMIP5 models, leading to a greater positive SW feedback. Note that the low-level cloud fraction simulated by NICAM is largely underestimated compared with satellite observations (Kodama et al. 2015). Comparison of Figs. 15 and 7 also indicates that the long-term climate-scale simulation is necessary to quantitatively assess cloud feedback and therefore climate sensitivity. For example, the total cloud feedback obtained from the short-term NICAM 


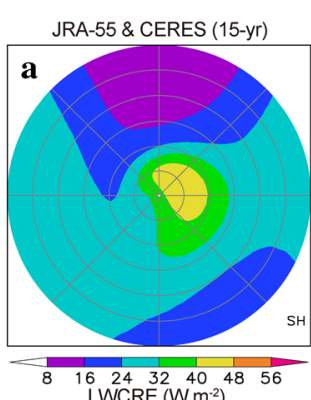

1624324048
LWCRE $\left(W^{-2}\right)^{2}$

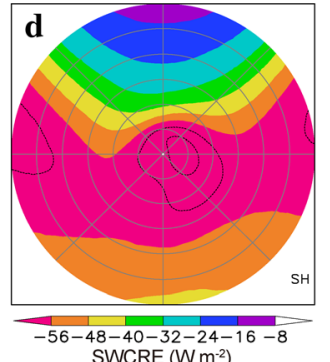

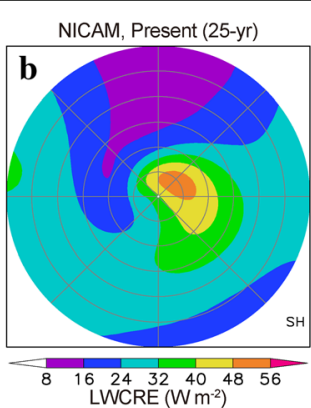

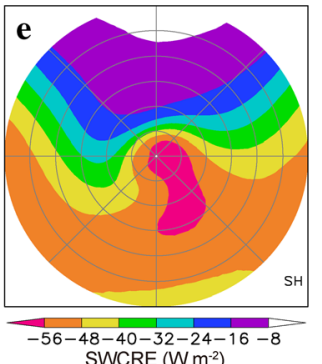

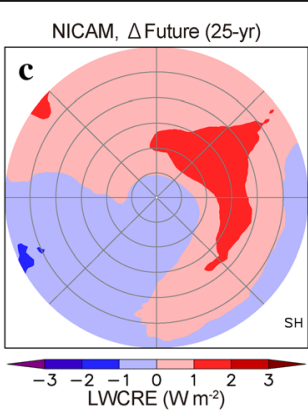

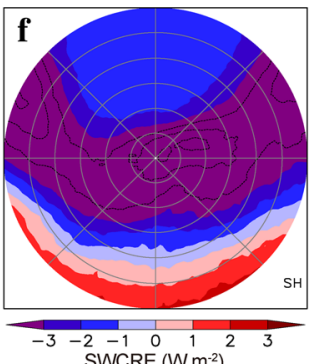

Fig. 13 Composite of longwave and shortwave cloud radiative effects averaged over extratropical cyclones in the southern hemisphere. a, d JRA55 reanalysis and CERES computed product for March 2000 to February 2015. b, e NICAM for 1979-2003. c, f NICAM for 2075-2099 minus that for 1979-2003. In addition to color scales, additional contours are added in $\mathbf{d}$ and $\mathbf{f}$; contours show -64 and $-72 \mathrm{~W} \mathrm{~m}^{-2}$ in $\mathbf{d}$ and -4 , -5 and $6 \mathrm{~W} \mathrm{~m}^{-2}$ in $\mathbf{f}$. The concentric gray circles represent increments of $500 \mathrm{~km}$ from the center of extratropical cyclones. The composites are meridionally reversed, and gray straight lines indicate (clockwise from top) poleward, pole-eastward, eastward, equator-eastward, equatorward, equator-westward, westward, and pole-westward directions from the center of extratropical cyclones

simulation (Fig. 7) is greater than that obtained in almost all the CMIP3 and CMIP5 models, whereas the total cloud feedback from the long-term NICAM climate simulation (Fig. 15) is comparable with that of the CMIP3 and CMIP5 model ensembles.

In the near future, historical simulations using NICAM with 56,28 , and $14 \mathrm{~km}$ meshes will be performed under the protocol of the Coupled Model
Intercomparison Project Phase 6 (CMIP6) High Resolution Model Intercomparison Project (HighResMIP; Haarsma et al. 2016). The use of multiple horizontal resolutions may provide us with an explanation of the different cloud responses among GCMs and NICAM (and global cloud-system resolving models). The influence of vertical resolution on cloud feedback should also be investigated, as a vertical resolution of $400 \mathrm{~m}$ a LWCRE/JetLat $(-0.07)$

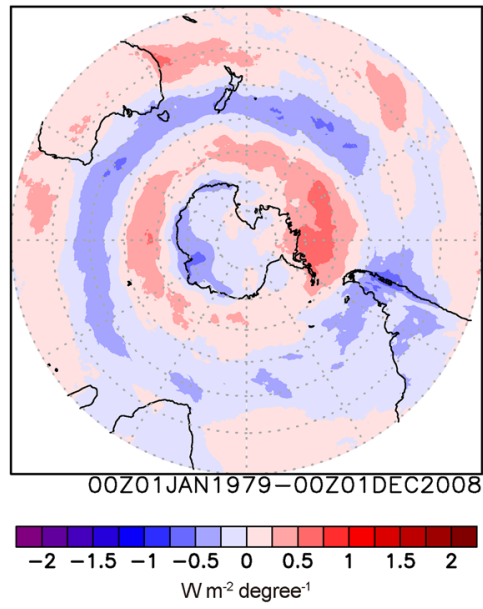

b SWCRE/JetLat $(-0.18)$

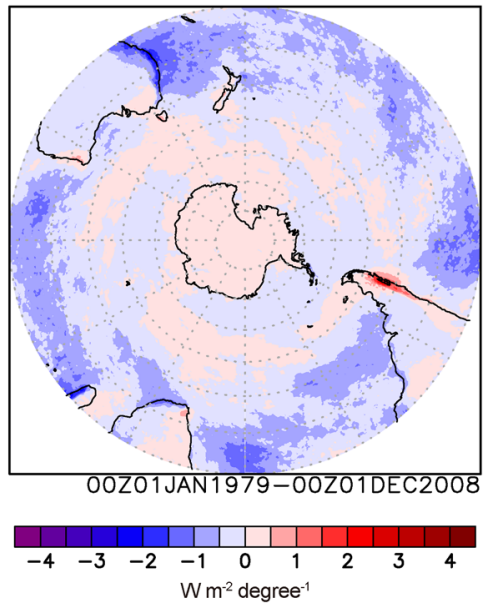

Fig. 14 Response of cloud radiative effects to poleward jet shift in a present-day climate simulation $\left(\mathrm{W} \mathrm{m}^{-2}\right.$ degree $\left.{ }^{-1}\right)$. a Longwave cloud radiative effects (LWCRE); $\mathbf{b}$ shortwave cloud radiative effects (SWCRE). Gray dotted circles represent latitudes in $10^{\circ}$ increments between $20^{\circ} \mathrm{S}$ and $80^{\circ} \mathrm{S}$. Values at the top of each panel are spatial mean regressions averaged over $30^{\circ} \mathrm{S}-60^{\circ} \mathrm{S}$. See main text for analysis method 


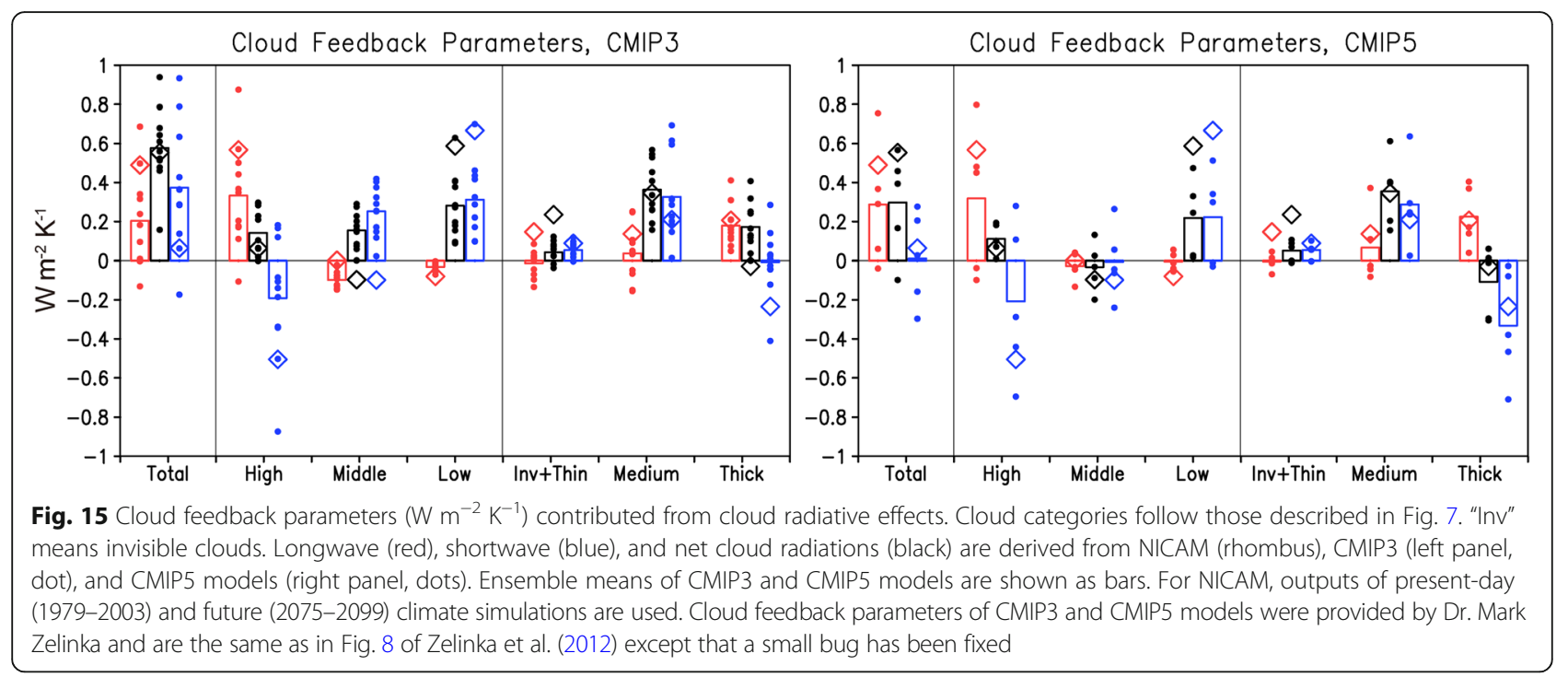

is necessary to resolve cirrus clouds (Seiki et al. 2015b). The HighResMIP simulation, which covers 1950-2014, will also provide us with the first opportunity to discuss decadal variability using a global cloud-system resolving model. For example, Zhou et al. (2016) analyzed their own historical and future climate simulations by using a GCM and found that the cloud feedback parameter derived from the recent 30 -year simulation is smaller than that from the recent 100-year and future climate simulations, seemingly due to a different spatial pattern of SST rise.

Constraining climate sensitivity using observation is also of great interest to reduce uncertainty in climate sensitivity. It has been suggested from observed interannual variability that high-level cloud fraction tends to decrease as SST increases (Zelinka and Hartmann 2011; Su et al. 2017). By breaking down high-cloud change into optical depth, however, cirrus cloud can cause a significant increase in cloud radiative feedback (Zhou et al. 2014). Recent analysis found that a net decrease in tropical high-cloud fraction is due to a compensation of a decrease in cirrostratus and deep convective clouds and an increase in cirrus cloud, and that the relationship between near-global mean high-cloud fraction and SST are insignificant (Liu et al. 2017). These similarities and differences among observations, NICAM, and GCMs should be further investigated to offer clues to reducing uncertainty in climate sensitivity.

\section{Future directions}

Despite the outcomes of the SOUSEI project, we acknowledge the need for further studies in some areas. One of these areas concerns an increased high-cloud coverage due to global warming, as analyzed by Chen et al. (2016). The NICAM simulations show an increase in high-cloud coverage together with a reduction in IWP in the tropics. We need to understand the relationship between changes in IWP and cloud coverage in the tropics, how this response is consistent with observations, and whether it is robust or different among other climate models. For example, Satoh et al. (2012) used a simple model to find that reduced convective mass fluxes led to less IWP. Bony et al. (2016) compared the results of GCMs that were run in a radiative-convective equilibrium (RCE) configuration and found that GCMs generally showed reduction of high-cloud coverage. They attribute this partly to a reduced divergent flow near the tropopause, which is caused by reduced convective mass flux in a stabilized atmosphere, and partly to aggregation of convective clouds. The response of high-cloud coverage shown by Bony et al. (2016) is opposite to that of NICAM. Noda et al. (2014) argued that the increase in high-cloud coverage in NICAM is due mainly to the contribution of smaller clouds and hence models with higher horizontal resolution may show a different response for high clouds. However, the mechanism of the dependency of cloud changes on cloud size is not well understood. The change in cloud size probability distribution is related to aggregation of convective clouds, and this issue has been studied most actively since a study on self-aggregation of convective cloud (Bretherton et al. 2005). Recently, Wing et al. (2018) proposed intercomparison experiments of RCE to comprehensively understand the response of convective clouds. RCE simulations with NICAM suggest that the response of high clouds in RCE are related to cloud microphysics processes and turbulence (Ohno and Satoh 2018). 
In terms of important research topics that should be addressed by the climate research community in the next decade, Bony et al. (2015) proposed a study on "Cloud, Circulation and Climate Sensitivity" as one of the WCRP Grand Challenges. In particular, they asked four questions: What role does convection play in cloud feedback? What controls the position, strength, and variability of storm tracks? What controls the position, strength, and variability of tropical rain belts? What role does convective aggregation play in climate? High-resolution global nonhydrostatic models, including NICAM, are expected to play increasingly important roles in answering these questions. In particular, remarkable progress in computer technology now enables global cloud-system-resolving simulations on a multi-decadal scale (e.g., Kodama et al. 2015). We now need to understand the robustness of cloud feedback processes by investigating differences between such high-resolution climate simulations and conventional GCM simulations.

To contribute to the forthcoming CMIP6 project (Eyring et al. 2016), we plan to conduct climate projection studies using NICAM in cooperation with the new call for climate projection studies in Japan, called the Integrated Research Program for Advancing Climate Models (referred to as the TOUGOU program ${ }^{5}$ ), which began in May 2017. As part of CMIP6, HighResMIP places more importance on higher resolution simulations to assess more detailed changes of extreme events (Haarsma et al. 2016), and we will be expected to contribute to it. We plan to perform a series of AMIP-type climate simulations using NICAM with 14, 28, and $56 \mathrm{~km}$ meshes under a protocol of HighResMIP in order to analyze cloud and precipitation changes and their relationships to large-scale circulations, as was analyzed using a previous data set (Noda and Satoh 2014; Noda et al. 2015).

Using a hierarchy of numerical models is also an effective way to accelerate improvements in our understanding of cloud responses to a warming world. Idealized frameworks such as aqua planet simulations would provide us with an essential mechanism to understand cloud response due to global warming (Miura et al. 2005; Stevens and Bony 2013; Kodama et al. 2014). In particular, a new intermodal comparison project using RCE simulations was recently initiated (Wing et al. 2018), and RCE results with NICAM (Ohno and Satoh 2018) show different high-cloud sensitivity to SST from those of GCMs (Bony et al. 2016). Climate research has suffered from the uncertainty of modeled cloud behavior and associated large-scale circulation fields even in the idealized aqua planet assumption, due to uncertainty arising from cumulus parameterization (Williamson et al. 2013; Stevens and Bony 2013). The use of high-resolution modeling that directly calculate cloud processes using cloud microphysics schemes without $\mathrm{cu}-$ mulus parameterization is expected to improve our understanding of cloud responses to global warming, further reducing the uncertainties derived from different model results.

Interaction between clouds and circulation in the storm-track region is one of the key challenges in the WCRP Grand Challenge, "Clouds, Circulation and Climate Sensitivity" (Bony et al. 2015). It is of great interest to investigate interaction among radiation, latent heat, and the development and track of extratropical cyclones using NICAM, which explicitly treats cloud microphysical processes without the aid of convection schemes. Latent heat may not only accelerate the development of extratropical cyclones but also affect their track and size. A baroclinic lifecycle experiment suggested a decrease in the horizontal scale of extratropical cyclones in a moister world (Booth et al. 2013). Li et al. (2015) showed suppression of the storm-track activity and a significant change in the zonal mean basic state by switching off cloud-radiation interactions in a GCM.

It is now possible to observe fine-scale horizontal and vertical structures of extratropical cyclones using high-resolution satellite data with active sensors. Some studies have evaluated cloud and precipitation processes around extratropical cyclone simulated by GCMs using CloudSat (Posselt et al. 2008; Naud et al. 2010; Field et al. 2011) and CALIPSO (Naud et al. 2010; Bodas-Salcedo et al. 2014). Now, the Global Precipitation Measurement (GPM) (Hou et al. 2014) radar products, which cover both the tropics and extratropics, are available, and the vertical structure of frontal precipitation in the extratropics simulated by $3.5 \mathrm{~km}$ mesh NICAM was evaluated as a case study (Kotsuki et al. 2014).

In the near future, the HighResMIP dataset will help us to improve our understanding of model bias including resolution dependency and confidence in future changes of cloud and precipitation associated with extratropical cyclones through more comprehensive analysis of the forthcoming high-resolution climate simulations.

\section{Conclusions}

This article reviews the outcomes of the NICAM subgroup of the 5-year SOUSEI program, which aimed to reduce the uncertainty in climate models due to cloud processes using a global non-hydrostatic model. NICAM was used to conduct numerical simulations with much higher resolution than conventionally used GCMs by explicitly calculating cloud processes using cloud microphysics schemes without a cumulus parameterization scheme. In NICAM, clouds are more realistically 
calculated with resolving meso-scale convective systems, and it is thought that uncertainties of cloud simulations derived from cumulus parameterizations are reduced.

In this review, we describe a newly developed double-moment bulk cloud microphysics scheme and stress importance of evaluation using satellite observation. We explore the uncertainties of the cloud microphysics scheme using a large-eddy simulation model and a kinematic model and compare it with a bin microphysics scheme. We discuss clouds and changes in weather systems, such as tropical and extratropical cyclones, using climate projection simulations by NICAM with the time-slice approach. In particular, we focus on changes in high clouds. Based on this work, we propose analysis using the size distribution of high clouds. We also discuss dependencies of high-cloud changes in experiments using two different microphysics schemes. Clouds, precipitation, and storm changes are also analyzed using the multi-decadal experiments by NICAM.

We estimated the cloud feedback parameters simulated by NICAM and discussed their uncertainties. Finally, we explore the prospects for research into global warming using NICAM, which are currently being pursued in the TOUGOU program.

It is thought that high-resolution global non-hydrostatic models without cumulus parameterization will reduce uncertainties due to clouds in estimates of cloud sensitivity. Although the ambiguities related to cumulus parameterization are absent, another type of uncertainty is introduced by the cloud microphysics schemes. However, clouds simulated by these models are more feasible to direct comparison and evaluation with satellite observational data, which cover the entire globe with high resolution. Comprehensive evaluations of simulated clouds are achievable using satellite simulators (Hashino et al. 2013). Cloud microphysics schemes also offer various choices for constructing schemes: classification of hydrometeors, number of moments of prognostic variables or treatment of size distributions of hydrometeors, and cloud habits such as shape and density. While double-moment bulk cloud microphysics schemes are expected to show good performance as shown in this study, single-moment bulk cloud microphysics schemes are still useful (Roh and Satoh 2014). Although bin cloud microphysics schemes used in high-resolution global models require computer power that is an order of magnitude larger than bulk cloud microphysics schemes, they are used as a reference for other simpler cloud microphysics schemes.

High-resolution global non-hydrostatic models capture meso-scale convective systems over the globe and then reproduce large-scale organized convective systems, including TCs, extratropical cyclones, and cloud clusters in the tropics. Evaluations of these meso-scale convective systems add another dimension to model evaluations, which were not possible for GCMs. Cloud size analysis is an example of the evaluation of cloud systems (Fig. 5). Through these efforts, the use of this type of high-resolution models will lead to reduction in the uncertainty in climate sensitivity related to cloud processes.

Even though high-resolution global non-hydrostatic models reproduce realistic cloud structure, they still have biases in climatology, such as distributions of precipitation (Kinter et al. 2013; Kodama et al. 2015). They still have other ambiguities of GCMs including shallow clouds and planetary boundary layer schemes. Coupling to ocean and land models also introduces sources of model bias. Although uncertainties related to cloud processes may be reduced, continuous efforts are required to improve model biases and total reproducibility of climatology. The new DYAMOND project ${ }^{6}$ involves the intercomparison of global non-hydrostatic models with mesh size less than $5 \mathrm{~km}$. Studies such as this one will help to elucidate the advantages and limitations of high-resolution global non-hydrostatic models.

\section{Endnotes}

${ }^{1}$ SOUSEI Program https://www.jamstec.go.jp/sousei/ eng/. Accessed 15 Oct 2018.

${ }^{2}$ Earth Simulator http://www.jamstec.go.jp/es/en/. Accessed 15 Oct 2018.

${ }^{3}$ CMIP5 https://cmip.llnl.gov/cmip5/. Accessed 15 Oct 2018.

${ }^{4}$ CFMIP2 https://www.earthsystemcog.org/projects/ cfmip/cfmip2-cmip5. Accessed 15 Oct 2018.

${ }^{5}$ TOUGOU program http://www.jamstec.go.jp/tougou/ eng/. Accessed 15 Oct 2018.

${ }^{6}$ DYAMOND https://www.esiwace.eu/services/dyamond. Accessed 15 Oct 2018.

\section{Appendix}

\section{Description of NDW6}

In the SOUSEI program, Seiki et al. (2014, 2015a, b) evaluated and improved the ice cloud microphysics in NDW6. Seiki et al. (2014) proposed a simple but efficient method to model non-sphericity of ice particles. Uncertainties in ice cloud modeling originate partly from the uncertainties in the interrelationships among the mass $x$, maximum dimension $D$, projected area to the flow (cross section) $A$, and terminal velocity of ice particles, which are generally determined according to in situ measurements (Ono 1969; Auer and Veal 1970; Locatelli and Hobbs 1974; Heymsfield and Kajikawa 1987; Mitchell 1996). In NDW6, the power law relationships between $x$ and $D$ and between $x$ and $A$ are assumed as follows: 

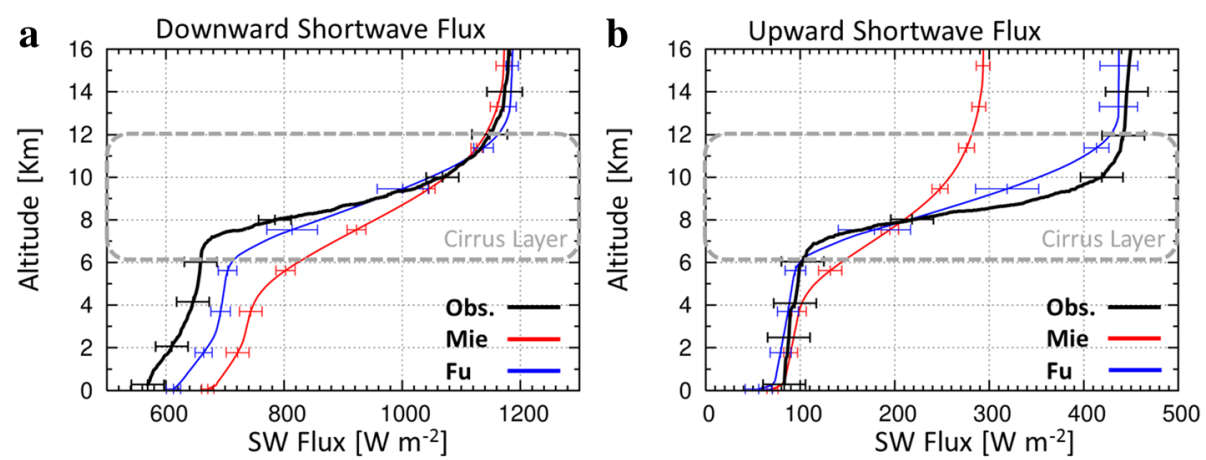

Fig. 16 The vertical profiles of shortwave fluxes. Downward shortwave flux $\mathbf{a}$ and upward shortwave flux $\mathbf{b}$ are shown for observation (black line) and for simulations using the radiation database calculated according to the Mie theory (red line) and the Fu database (blue line), assuming non-spherical particles. The error bars in the observed profiles indicate the estimated possible range, and in the simulated profiles indicate the standard deviation within the 63 sampled profiles. The gray dashed boxes indicate the cirrus layer. The simulated profiles are from the M92PLT experiment described in Seiki et al. (2014). The target cirrus clouds had an optical thickness of $6.1 \pm 0.5$ over the land around Japan $\left(30^{\circ} \mathrm{N}\right.$ to $40^{\circ} \mathrm{N}$ and $130^{\circ} \mathrm{E}$ to $142^{\circ} \mathrm{E}$ ) on 8 June 1995 . Adapted from Seiki et al. (2014)

$$
\begin{aligned}
& D=a_{D} x^{b_{D}}, \\
& A=a_{A} x^{b_{A}},
\end{aligned}
$$

where $a_{D}, b_{D}, a_{A}$, and $b_{A}$ are constants determined experimentally from in situ observations by Mitchell (1996). The terminal velocities of ice particles are approximated using values from a pre-calculated database according to the theoretical methodology proposed by Bohm (1989) and Mitchell (1996). Seiki et al. (2014) chose the assemblages of planer polycrystals in cirrus clouds for snow, lump graupel for graupel, and hexagonal columns for cloud ice (with hexagonal plate as an optional extra for cloud ice) from Mitchell's database, and the abovementioned power law relationships were defined for each hydrometeor category. Vapor deposition/sublimation, melting, collisional growth, and gravitational sedimentation were calculated using the power law relationships. In Seiki et al. (2015b), homogeneous ice nucleation was newly implemented by referring to Ren and MacKenzie (2005) and Kärcher et al. (2006). In addition, Seiki et al. (2015b) reduced the sticking efficiency to its lower limit at $253 \mathrm{~K}$ in ice crystal aggregation, because the parameterized sticking efficiency was originally determined by laboratory experiments within temperature ranges mostly between 253 and $273 \mathrm{~K}$ (see Figs. 14-18 in Pruppacher and Klett 1997).

The differences between the versions of NDW6 referred to in this review are summarized in Table 1. We used different versions of NDW6 from Seiki and Nakajima (2014), referred to as SN14; Seiki et al. (2014), referred to as S14; and Seiki et al. (2015b), referred to as S15. S14 used the same settings as P07COL in Seiki et al. (2014), and S15 used the same settings as G9CTL in Seiki et al. (2015b). These simulations were performed using NICAM with $14 \mathrm{~km}$ horizontal resolution and 40 vertical layers. Seiki et al. (2015b) also performed simulations with finer spatial resolution using the same settings as S15, except for the resolution. NICAM had 74 vertical layers in S15 V (the same as G9Z4 in Seiki et al. 2015b) and had 74 vertical layers with $7 \mathrm{~km}$ horizontal resolution in S15VH (the same as G10Z4 in Seiki et al. 2015b).

Seiki et al. (2014) calculated cloud optical properties (the volume extinction coefficient, the volume absorption coefficient, the asymmetry factor, and the second moment of phase function) and prepared a look-up table of the effective radius in the range from $1 \mu \mathrm{m}$ to $1 \mathrm{~mm}$ to cover precipitating hydrometeors for a broadband radiative transfer model MSTRNX (Sekiguchi and Nakajima 2008). The optical properties of cloud water and rain were calculated according to the Mie theory, and the optical properties of cloud ice, snow, and graupel (assuming non-spherical ice particles) were provided by $\mathrm{Fu}$ (1996) and $\mathrm{Fu}$ et al. (1998). This database of optical properties was first implemented in NDW6 and NSW6 (in 2014 and 2017, respectively; the range of the effective radii was limited to less than $80 \mu \mathrm{m}$ and all hydrometeors were assumed to be spherical).

It is significant that the asymmetry factor decreases as the aspect ratio departs from unity for non-spherical particles (e.g., Fu 2007), because the cloud albedo is known to increase as the asymmetry factor decreases (Liou 2002). Seiki et al. (2014) evaluated the improvement in the simulated radiative fluxes by using the $\mathrm{Fu}$ database for ice particles and comparing them to in situ balloon-borne sensor observations of cirrus clouds along a mid-latitude frontal system. They found that the simulated radiative fluxes using the Fu database, particularly in the SW range, were in good agreement with observations, in contrast to the simulated fluxes using the database calculated according to the Mie theory (see Fig. 16). 
When using the $\mathrm{Fu}$ database, the downward (upward) SW flux significantly decreases (increases) through the cirrus layer. The remaining differences between the simulated and observed SW fluxes originated from both model and observation errors and are discussed in Seiki et al. (2014).

\begin{abstract}
Abbreviations
AMIP: Atmospheric Model Intercomparison Project; CERES: Clouds and the Earth's Radiant Energy System; CFMIP2: The Cloud Feedback Model Intercomparison Project Phase 2; CFODD: Contoured frequency by optical depth; CMIP3: Coupled Model Intercomparison Project Phase 3; CMIP5: Coupled Model Intercomparison Project Phase 5; CMIP6: Coupled Model Intercomparison Project Phase 6; COD: Cloud optical depths; CTL: Control simulation; CTP: Cloud top pressure; DJF: December-JanuaryFebruary; DM: Double-moment bulk cloud microphysics scheme; DYAMOND: DYnamics of the Atmospheric general circulation Modeled On Non-hydrostatic Domains; ERA-Interim: European Centre for Medium-Range Weather Forecasts interim reanalysis; FAT: Fixed anvil temperature; GCM: General circulation model; GPM: Global Precipitation Measurement; GW: Global warming simulation; HighResMIP: High Resolution Model Intercomparison Project; ISCCP: International Satellite Cloud Climatology Project; ISO: Intra-seasonal oscillations; ITCZ: Intertropical Convergence Zone; IWC: Ice water content; IWP: Ice water path; JAMSTEC : Japan Agency for Marine-Earth Science and Technology; JJA: June-July-August; KiD: The Kinetic Driver; LES: Large-eddy simulation; LW: Longwave; LWCRF: Longwave cloud radiative forcing; MAM: March-April-May; NDW6: NICAM doublemoment water 6 cloud microphysics scheme; Nl: Ice number concentration; NICAM: Non-hydrostatic icosahedral atmospheric model; NOAA: National Oceanic and Atmospheric Administration; NSW6: NICAM single-moment water 6 cloud microphysics scheme; OLR: Outgoing longwave radiation; PD: Present-day simulation; RCE: Radiative-convective equilibrium; REI: Ice effective radius; RICO: Rain in Cumulus over the Ocean; SCALE: Scalable Computing for Advanced Library and Environment; SM: Single-moment bulk cloud microphysics scheme; SON: September-October-November; SPCAM: Superparameterized Community Atmosphere Model; SST: Sea surface temperature; SW: Shortwave; TC: Tropical cyclone; TRMM: Tropical Rainfall Measuring Mission; WCRP: World Climate Research Program
\end{abstract}

\section{Acknowledgements}

This work is supported by the Program for Risk Information on Climate Change (SOUSEI) and the Integrated Research Program for Advancing Climate Models (TOUGOU) funded by the Ministry of Education, Culture, Sports, Science, and Technology (MEXT), Japan. The NICAM simulations of NDW6 were performed on the Earth Simulator at Japan Agency for MarineEarth Science and Technology (JAMSTEC). The development of NICAM used in this study and its experiments were conducted in part by the Strategic Programs for Innovative Research (SPIRE) Field 3 (Projection of Planet Earth Variations for Mitigating Natural Disasters), which is promoted by MEXT. The contributions of all the members of the NICAM development team, particularly for Dr. Hisashi Yashiro, are greatly appreciated. The numerical simulation by Kodama et al. (2015) and the NICAM simulations of NSW6 in Chen et al. (2016) were performed on the K computer at the RIKEN Advanced Institute for Computational Science (Proposal numbers hp120279, hp120313, hp130010, hp140219, and hp150213). This review was also supported by SCALE library, which was developed by Team-SCALE of RIKEN Advanced Institute for Computational Sciences (http://scale.aics.riken.jp). The data from the Global Energy and Water Exchange Project (GEWEX) Cloud System Study (GCSS) intercomparison studies, which we used in several figures, were downloaded from http://projects.knmi.nl/rico/.

\section{Funding}

This study was supported by the Program for Risk Information on Climate Change (SOUSEI) and Integrated Research Program for Advancing Climate Model (TOUGOU), which are promoted by the Ministry of Education, Culture, Sports, Science and Technology (MEXT), Japan.

\section{Availability of data and materials}

The NICAM data simulated by the K computer will be available. The following paper is to be submitted and is referred to as personal communication in the text. Please contact the authors for these data and unpublished manuscripts.

Kuba et al. (2018) Evaluation of rain microphysics using radar simulator and numerical models: comparison between a two-moment bulk and a spectral bin cloud microphysics schemes, in preparation.

\section{Authors' contributions}

MS led the studies using NICAM in the SOUSEl program and coordinated this review. AN is leading the NICAM studies in the follow-up TOUGOU program. MS contributed to the sections "Introduction," subsection "Future directions" of the section "Discussion," and the section "Summary." TS is responsible for the subsection "Development of a double-moment cloud microphysics scheme" in the section "Review." In the subsection "Sensitivity of cloud microphysics schemes," "A large-eddy simulation model" was contributed by YS and "Comparison with a bin microphysics scheme" by NK. In the subsection "Cloud and circulation changes," "Climate projection simulations by NICAM" was contributed by MS and AN, "Changes of size distribution of high clouds" by AN, "High cloud changes in two different microphysics scheme experiments" by YC, "Clouds, precipitation, and storm changes in the multi-decadal experiments" by CK and YY, and "Storm track and its cloud radiative effect" by CK, who also contributed to "Cloud feedback" in the subsection "Discussion." The numerical simulations of the multidecadal NICAM experiments were conducted mainly by YY, CK, and AN. All authors read and approved the final manuscript.

\section{Authors' information}

MS started development of NICAM around the year 2000, and since then the NICAM studies have been conducted mainly in three institutes: Atmosphere and Ocean Research Institute of the University of Tokyo, JAMSTEC, and the Advanced Institute for Computational Science, RIKEN (currently, RIKEN Center for Computational Science).

Ethics approval and consent to participate

Not applicable.

\section{Consent for publication}

All the figures in this paper are permitted to be used by the copyright holders of the original manuscripts.

\section{Competing interests}

The authors declare that they have no competing interests.

\section{Publisher's Note}

Springer Nature remains neutral with regard to jurisdictional claims in published maps and institutional affiliations.

\section{Author details \\ ${ }^{1}$ Atmosphere and Ocean Research Institute, The University of Tokyo, 5-1-5 Kashiwanoha, Kashiwa, Chiba 277-8568, Japan. ${ }^{2}$ Japan Agency for Marine-Earth Science and Technology, 3173-15, Showa-machi, Kanazawa-ku, Yokohama, Kanagawa 236-0001, Japan. ${ }^{3}$ Department of Applied Energy, Graduate School of Engineering, Nagoya University, Furo cho, Chikusa-ku, Nagoya, Aichi 464-8603, Japan. ${ }^{4}$ RIKEN Center for Computational Science, 7-1-26, Minatojima-minami-machi, Chuo-ku, Kobe, Hyogo 650-0047, Japan.}

Received: 25 June 2018 Accepted: 8 October 2018

Published online: 29 October 2018

References

Ackerman AS, van Zanten MC, Stevens B, Savic-Jovcic V, Bretherton CS, Chlond A, Golaz J-C, Jiang H, Khairoutdinov M, Krueger S, Lewellen DC, Lock A, Moeng C-H, Nakamura K, Petters MD, Snider JR, Weinbrecht S, Zulauf M (2009) Large-eddy simulations of a drizzling, stratocumulus-topped marine boundary layer. Mon Weather Rev 137:1083-1110. https://doi.org/10.1175/ 2008MWR2582.1

Auer AH, Veal DL (1970) The dimension of ice crystals in natural clouds. J Atmos Sci 27:919-926

Bengtsson L, Hodges Kl, Keenlyside N (2009) Will extratropical storms intensify in a warmer climate? J Clim 22:2276-2301. https://doi.org/10.1175/ 2008JCLI2678.1 
Blossey PN, Bretherton CS, Zhang M, Cheng A, Endo S, Heus T, Liu Y, Lock AP, De Roode SP, Xu K-M (2013) Marine low cloud sensitivity to an idealized climate change: the CGILS LES intercomparison. J Adv Model Earth Syst 5:234-258. https://doi.org/10.1002/jame.20025

Bodas-Salcedo A, Andrews T, Karmalkar AV, Ringer MA (2016) Cloud liquid water path and radiative feedbacks over the Southern Ocean. Geophys Res Lett 43: 10938-10946. https://doi.org/10.1002/2016GL070770

Bodas-Salcedo A, Williams KD, Ringer MA, Beau I, Cole JNS, Dufresne J-L, Koshiro T, Stevens B, Wang Z, Yokohata T (2014) Origins of the solar radiation biases over the Southern Ocean in CFMIP2 models. J Clim 27:41-56. https://doi.org/ 10.1175/JCLI-D-13-00169.1

Bohm HP (1989) A general equation for the terminal fall speed of solid hydrometeors. J Atmos Sci 45:2419-2427. https://doi.org/10.1175/1520-0469(1989)046<2419: AGEFIT $>2.0 . \mathrm{CO} ; 2$

Bony S, Stevens B, Coppin D, Becker T, Reed KA, Voigt A, Medeiros B (2016) Thermodynamic control of anvil cloud amount. Proc Natl Acad Sci U S A 113:8927-8932. https://doi.org/10.1073/pnas.1601472113

Bony S, Stevens B, Frierson DMW, Jakob C, Kageyama M, Pincus R, Shepherd TG, Sherwood SC, Siebesma AP, Sobel AH, Watanabe M, Webb MJ (2015) Clouds, circulation and climate sensitivity. Nat Geosci 8:261-268. https://doi.org/10. 1038/ngeo2398

Booth JF, Wang S, Polvani L (2013) Midlatitude storms in a moister world: lessons from idealized baroclinic life cycle experiments. Clim Dyn 41:787-802. https://doi.org/10.1007/s00382-012-1472-3

Boucher $O$, Randall D, Artaxo P, Bretherton C, Feingold F, Forster $P$, Kerminen VM, Kondo Y, Liao H, Lohmann U, Rasch P, Satheesh SK, Sherwood S, Stevens B, Zhang XY (2013) Clouds and aerosols. In: Stocker TF, Qin D, Plattner GK, Tignor M, Allen SK, Boschung J, Nauels A, Xia Y, Bex V, Midgley PM (eds) Climate change 2013: the physical science basis. Contribution of Working Group I to the Fifth Assessment Report of the Intergovernmental Panel on Climate Change. Cambridge University Press, Cambridge

Bretherton CS (2015) Insights into low-latitude cloud feedbacks from highresolution models. Phil Trans R Soc A 373:20140415. https://doi.org/10.1098/ rsta.2014.0415

Bretherton CS, Blossey P, Khairoutdinov M (2005) An energy-balance analysis of deep convective self-aggregation above uniform SST. J Atmos Sci 62:42734292. https://doi.org/10.1175/JAS3614.1

Bretherton CS, Krueger SK, Wyant MC, Bechtold P, Van Meijgaard E, Stevens TJ (1999b) A GCSS boundary-layer cloud model intercomparison study of the first ASTEX Lagrangian experiment. Bound-Layer Meteorol 93:341-380. https://doi.org/10.1023/A:1002005429969

Bretherton CS, Macvean M, Bechtold P, Chlond A, Cotton WR, Cuxart J, Cuijpers $H$, Mhairoutdinov M, Kosovic B, Lewellen D, Moeng C-H, Siebesma P, Stevens B, Stevens DE, Sykes I, Wyant MC (1999a) An intercomparison of radiatively driven entrainment and turbulence in a smoke cloud, as simulated by different numerical models. Q J R Meteorol Soc 125:391-423. https://doi.org/ 10.1002/qj.49712555402

Ceppi P, Hartmann DL, Webb MJ (2015) Mechanisms of the negative shortwave cloud feedback in high latitudes. J Clim 29:139-157. https://doi.org/10.1175/ JCLI-D-15-0327.1

Champion AJ, Hodges KI, Bengtsson LO, Keenlyside NS, Esch M (2011) Impact of increasing resolution and a warmer climate on extreme weather from northern hemisphere extratropical cyclones. Tellus A Dyn Meteorol Oceanogr 63:893-906. https://doi.org/10.1111/j.1600-0870.2011.00538.x

Chen J-P, Lamb D (1994a) The theoretical basis for the parameterization of ice crystal habits: growth by vapor deposition. J Atmos Sci 51:1206-1221. https://doi.org/10.1175/1520-0469(1994)051<1206:TTBFTP > 2.0.CO;2

Chen J-P, Lamb D (1994b) Simulation of cloud microphysical and chemical processes using a multicomponent framework. Part I: description of the microphysical model. J Atmos Sci 51:2613-2630. https://doi.org/10.1175/ 1520-0469(1994)051<2613:SOCMAC>2.0.CO;2

Chen J-P, Lamb D (1999) Simulation of cloud microphysical and chemical processes using a multicomponent framework. Part II: microphysical evolution of a wintertime orographic cloud. J Atmos Sci 56:2293-2312. https://doi.org/10.1175/1520-0469(1999)056<2293:SOCMAC>2.0.CO;2

Chen T, Rossow WB, Zhang Y (2000) Radiative effects of cloud-type variations. J Clim 13:264-286. https://doi.org/10.1175/1520-0442(2000)013<0264: REOCTV>2.0.CO;2

Chen Y-W, Seiki T, Kodama C, Satoh M, Noda AT, Yamada Y (2016) High cloud responses to global warming simulated by two different cloud microphysics schemes implemented in the nonhydrostatic icosahedral atmospheric model (NICAM). J Clim 29:5949-5964. https://doi.org/10.1175/JCLI-D-15-0668.1

Collins WD, Satoh M (2009) Simulating global clouds, past, present, and future. In: Heintzenberg J, Charlson RJ (eds) Clouds in the perturbed climate system: their relationship to energy balance, atmospheric dynamics, and precipitation, Struengmann forum report, vol 2. MIT Press, Cambridge

Doelling DR, Loeb NG, Keyes DF, Nordeen ML, Morstad D, Nguyen C, Wielicki BA, Young DF, Sun M (2013) Geostationary enhanced temporal interpolation for CERES flux products. J Atmos Ocean Technol 30:1072-1090. https://doi.org/ 10.1175/JTECH-D-12-00136.1

Dufresne J-L, Bony S (2008) An assessment of the primary sources of spread of global warming estimates from coupled atmosphere-ocean models. J Clim 21:5135-5144. https://doi.org/10.1175/2008JCLI2239.1

Eyring V, Bony S, Meehl GA, Senior CA, Stevens B, Stouffer RJ, Taylor KE (2016) Overview of the coupled model intercomparison project phase 6 (CMIP6) experimental design and organization. Geosci Model Dev 9:1937-1958. https://doi.org/10.5194/gmd-9-1937-2016

Field PR, Bodas-Salcedo A, Brooks ME (2011) Using model analysis and satellite data to assess cloud and precipitation in midlatitude cyclones. Q J R Meteorol Soc 137:1501-1515. https://doi.org/10.1002/qj.858

Flato G, Marotzke J, Abiodun B, Braconnot P, Chou SC, Collins W, Cox P, Driouech F, Emori S, Eyring V, Forest C, Gleckler P, Guilyardi E, Jakob C, Kattsov V, Reason C, Rummukainen M (2013) Evaluation of climate models. In: Climate change 2013: the physical science basis. Contribution of working group I to the fifth assessment report of the Intergovernmental Panel on Climate Change. Cambridge University Press, Cambridge

Fu Q (1996) An accurate parameterization of the solar radiative properties of cirrus clouds for climate models. J Atmos Sci 9:2058-2082. https://doi.org/10. 1175/1520-0442(1996)009<2058:AAPOTS>2.0.CO;2

Fu Q (2007) A new parameterization of an asymmetry factor of cirrus clouds for climate models. J Atmos Sci 64:4140-4150. https://doi.org/10.1175/ 2007JAS2289.1

Fu Q, Yang P, Sun WB (1998) An accurate parameterization of the infrared radiative properties of cirrus clouds for climate models. J Clim 11:2223-2237. https://doi.org/10.1175/1520-0442(1998)011<2223:AAPOT|>2.0.CO;2

Geng Q, Sugi M (2003) Possible change of extratropical cyclone activity due to enhanced greenhouse gases and sulfate aerosols - study with a highresolution AGCM. J Clim 16:2262-2274. https://doi.org/10.1175/15200442(2003)16<2262:PCOECA >2.0.CO;2

Grabowski WW (1998) Toward cloud resolving modeling of large-scale tropical circulation: a simple cloud microphysics parameterization. J Atmos Sci 55:32833298. https://doi.org/10.1175/1520-0469(1998)055<3283:TCRMOL>2.0.CO;2

Grabowski WW (2016) Separating dynamical and microphysical impacts of aerosols on deep convection applying piggybacking methodology. In: The European Geosciences Union General Assembly, Vienna, Austria, 17-22 April 2016

Grabowski WW, Morrison H (2016) Untangling microphysical impacts on deep convection applying a novel modeling methodology. Part II: double-moment microphysics. J Atmos Sci 73:3749-3770. https://doi.org/10.1175/JAS-D-150367.1

Grise KM, Polvani LM (2014) Southern hemisphere cloud-dynamics biases in CMIP5 models and their implications for climate projections. J Clim 27:60746092. https://doi.org/10.1175/JCLI-D-14-00113.1

Guo H, Golaz J-C, Donner LJ (2011) Aerosol effects on stratocumulus water paths in a PDF-based parameterization. Geophys Res Lett 38:L17808. https://doi. org/10.1029/2011GL048611

Haarsma RJ, Roberts MJ, Vidale PL, Senior CA, Bellucci A, Bao Q, Chang P, Corti S, Fučkar NS, Guemas V, von Hardenberg J, Hazeleger W, Kodama C, Koenigk T, Leung LR, Lu J, Luo J-J, Mao J, Mizielinski MS, Mizuta R, Nobre P, Satoh M, Scoccimarro E, Semmler T, Small J, von Storch J-S (2016) High resolution model Intercomparison project (HighResMIP v1.0) for CMIP6. Geosci Model Dev 9:4185-4208. https://doi.org/10.5194/gmd-9-4185-2016

Harada Y, Kamahori H, Kobayashi C, Endo H, Kobayashi S, Ota Y (2016) The JRA-55 reanalysis: representation of atmospheric circulation and climate variability. J Meteorol Soc Jpn 94:269-302. https://doi.org/10.2151/jmsj. 2016-015

Harrington JY, Sulia K, Morrison H (2013a) A method for adaptive habit prediction in bulk microphysical models. Part I: theoretical development. J Atmos Sci 70: 349-364. https://doi.org/10.1175/JAS-D-12-040.1

Harrington JY, Sulia K, Morrison H (2013b) A method for adaptive habit prediction in bulk microphysical models. Part II: parcel model corroboration. J Atmos Sci 70:365-376. https://doi.org/10.1175/JAS-D-12-0152.1 
Hartmann DL, Larson K (2002) An important constraint on tropical cloud-climate feedback. Geophys Res Lett 29:12-1-12-4. https://doi.org/10.1029/ 2002GL015835

Hartmann DL, Ockert-Bell ME, Michelsen ML (1992) The effect of cloud type on Earth's energy balance: global analysis. J Clim 5:1281-1304. https://doi.org/10. 1175/1520-0442(1992)005<1281:TEOCTO>2.0.CO;2

Hashino T, Satoh M, Hagihara Y, Kato S, Kubota T, Matsui T, Nasuno T, Okamoto $H$, Sekiguchi M (2016) Evaluating arctic cloud radiative effects simulated by NICAM with A-train. J Geophys Res Atmos 121:7041-7063. https://doi.org/10. 1002/2016JD024775

Hashino T, Satoh M, Hagihara $Y$, Kubota T, Matsui T, Nasuno T, Okamoto H (2013) Evaluating cloud microphysics from NICAM against CloudSat and CALIPSO. J Geophys Res Atmos 118:7273-7292. https://doi.org/10.1002/ jgrd.50564

Hashino T, Tripoli GJ (2007) The spectral ice habit prediction system (SHIPS). Part I: model description and simulation of the vapor deposition process. J Atmos Sci 64:2210-2237. https://doi.org/10.1175/JAS3963.1

Hashino T, Tripoli GJ (2008) The spectral ice habit prediction system (SHIPS). Part II: simulation of nucleation and depositional growth of polycrystals. J Atmos Sci 65:3071-3094. https://doi.org/10.1175/2008JAS2615.1

Hashino T, Tripoli GJ (2011a) The spectral ice habit prediction system (SHIPS). Part III: description of the ice particle model and the habit-dependent aggregation model. J Atmos Sci 68:1125-1141. https://doi.org/10.1175/ 2011JAS3666.1

Hashino T, Tripoli GJ (2011b) The spectral ice habit prediction system (SHIPS). Part IV: box model simulations of the habit-dependent aggregation process. J Atmos Sci 68:1142-1161. https://doi.org/10.1175/2011JAS3667.1

Heymsfield AJ, Kajikawa M (1987) An improved approach to calculating terminal velocities of plate-like crystals and graupel. J Atmos Sci 44:1088-1099. https://doi.org/10.1175/1520-0469(1987)044<1088:AIATCT>2.0.CO;2

Hill AA, Shipway BJ, Boutle IA (2015) How sensitive are aerosol-precipitation interactions to the warm rain representation? J Adv Model Earth Syst 7:9871004. https://doi.org/10.1002/2014MS000422

Hong S-Y, Dudhia J, Chen S-H (2004) A revised approach to ice microphysical processes for the bulk parameterization of clouds and precipitation. Mon Weather Rev 132:103-120. https://doi.org/10.1175/1520-0493(2004)132,0103: ARATIM.2.0.CO;2

Hou AY, Kakar RK, Neeck S, Azarbarzin AA, Kummerow CD, Kojima M, Oki R, Nakamura K, Iguchi T (2014) The global precipitation measurement mission. Bull Am Meteorol Soc 95:701-722. https://doi.org/10.1175/BAMS-D-13-00164.

Iga S, Tomita H, Tsushima Y, Satoh M (2007) Climatology of a nonhydrostatic global model with explicit cloud processes. Geophys Res Lett 34:L22814. https://doi.org/10.1029/2007GL031048

Iga S, Tomita H, Tsushima Y, Satoh M (2011) Sensitivity of Hadley circulation to physical parameters and resolution through changing upper-tropospheric ice clouds using a global cloud-system resolving model. J Clim 24:2666-2679. https://doi.org/10.1175/2010JCLI3472.1

Igel AL, Igel MR, Van den Heever SC (2015) Make it a double? Sobering results from simulations using single-moment microphysics schemes. J Atmos Sci 72:910-925. https://doi.org/10.1175/JAS-D-14-0107.1

Inoue T, Satoh M, Miura H, Mapes B (2008) Characteristics of cloud size of deep convection simulated by a global cloud resolving model over the western tropical Pacific. J Meteorol Soc Jpn 86A:1-15. https://doi.org/10.2151/jmsj. 86A.1

Jensen EJ, Kinne S, Toon OB (1994) Tropical cirrus cloud radiative forcing: sensitivity studies. Geophys Res Lett 21:2023-2026. https://doi.org/10.1029/ 94GL01358

Jiang JH, Su H, Zhai C, Perun VS, Genio AD, Nazarenko LS, Donner LJ, Horowitz L, Seman C, Cole J, Gettelman A, Ringer MA, Rotstayn L, Jeffrey S, Wu T, Brient F, Dufresne J-L, Kawai H, Koshiro T, Watanabe M, LÉcuyer TS, Volodin EM, Iversen T, Drange H, Mesquita MDS, Read WG, Waters JW, Tian B, Teixeira J, Stephens GL (2012) Evaluation of cloud and water vapor simulations in CMIP5 climate models using NASA A-train satellite observations. J Geophys Res 117:D14105. https://doi.org/10.1029/2011JD017237

Kärcher B, Hendricks J, Lohmann U (2006) Physically based parameterization of cirrus cloud formation for use in global atmospheric models. J Geophys Res 111:D01205. https://doi.org/10.1029/2005JD006219

Kessler E (1969) On the distribution and continuity of water substance in atmospheric circulations. In: Meteorological monographs, no. 32. American Meteorological Society, Boston
Kinter JL, Cash B, Achuthavarier D, Adams J, Altshuler E, Dirmeyer P, Doty B, Huang B, Jin EJ, Marx L, Manganello J, Stan C, Wakefield T, Palmer T, Hamrud M, Jung T, Miller M, Towers P, Wedi N, Satoh M, Tomita H, Kodama C, Nasuno T, Oouchi K, Yamada Y, Taniguchi H, Andrews P, Baer T, Ezell M, Halloy C, John D, Loftis B, Mohr R, Wong K (2013) Revolutionizing climate modeling with project Athena: A multi-institutional, international collaboration. Bull Amer Meteorol Soc 94:231-245. https://doi.org/10.1175/ BAMS-D-11-00043.1.

Klein SA, Hall A (2015) Emergent constraints for cloud feedbacks. Current Climate Change Reports 1:276-287. https://doi.org/10.1007/s40641-015-0027-1

Klein SA, Jakob C (1999) Validation and sensitivities of frontal clouds simulated by ECMWF model. Mon Weather Rev 127:2514-2531. https://doi.org/10.1175/ 1520-0493(1999) 127<2514:VASOFC >2.0.CO;2

Knutson TR, McBride JL, Chan J, Emanuel K, Holland G, Landsea C, Held I, Kossin JP, Srivastava K, Sugi M (2010) Tropical cyclones and climate change. Nat Geosci 3:157-163. https://doi.org/10.1038/ngeo779

Kobayashi S, Ota Y, Harada Y, Ebita A, Moriya M, Onoda H, Onogi K, Kamahori H, Kobayashi C, Endo H, Miyaoka K, Takahashi K (2015) The JRA-55 reanalysis: general specifications and basic characteristics. J Meteorol Soc Japan 93:5-48. https://doi.org/10.2151/jmsj.2015-001

Kodama C, Iga S, Satoh M (2014) Impact of the sea surface temperature rise on storm-track clouds in global non-hydrostatic aqua-planet simulations. Geophys Res Lett 41:3545-3552. https://doi.org/10.1002/2014GL059972

Kodama C, Noda AT, Satoh M (2012) An assessment of the cloud signals simulated by NICAM using ISCCP, CALIPSO, and CloudSat satellite simulators. J Geophys Res 117:D12210. https://doi.org/10.1029/2011JD017317

Kodama C, Yamada Y, Noda AT, Kikuchi K, Kajikawa Y, Nasuno T, Tomita T, Yamaura T, Takahashi HG, Hara M, Kawatani Y, Satoh M, Sugi M (2015) A 20year climatology of a NICAM AMIP-type simulation. J Meteorol Soc Japan 93: 393-424. https://doi.org/10.2151/jmsj.2015-024

Kotsuki S, Terasaki K, Miyoshi T (2014) GPM/DPR precipitation compared with a 3. 5-km-resolution NICAM simulation. SOLA 10:204-209. https://doi.org/10.2151/ sola.2014-043

Kuba N, Fujiyoshi Y (2006) Development of a cloud microphysical model and parameterizations to describe the effect of CCN on warm cloud. Atmos Chem Phys 6:2793-2810. https://doi.org/10.5194/acp-6-2793-2006

Kuba N, Hashino T, Satoh M, Suzuki K (2014) Relationships between layer-mean radar reflectivity and columnar effective radius of warm cloud: numerical study using a cloud microphysical bin model. J Geophys Res Atmos 119: 3281-3294. https://doi.org/10.1002/2013JD020276

Kuba N, Murakami M (2010) Effect of hygroscopic seeding on warm rain clouds numerical study using a hybrid cloud microphysical model. Atmos Chem Phys 10:3335-3351. https://doi.org/10.5194/acp-10-3335-2010

Kuba N, Suzuki K, Hashino T, Seiki T, Satoh M (2015) Numerical experiments to analyze cloud microphysical processes depicted in vertical profiles of radar reflectivity of warm clouds. J Atmos Sci 72:4509-4528. https://doi.org/10. 1175/JAS-D-15-0053.1

Lang SE, Tao W-K, Chern J-D, Wu D, Li X (2014) Benefits of a fourth ice class in the simulated radar reflectivities of convective systems using a bulk microphysics scheme. J Atmos Sci 71:3583-3612. https://doi.org/10.1175/JASD-13-0330.1

Li J-LF, Waliser DE, Chen W-T, Ghan B, Kubar T, Stephens G, Ma H-Y, Deng M, Donner L, Seman C, Horowitz L (2012) An observationally based evaluation of cloud ice water in CMIP3 and CMIP5 GCMs and contemporary reanalyses using contemporary satellite data. J Geophys Res 117:D16105. https://doi. org/10.1029/2012JD017640

Li J-LF, Waliser DE, Stephens G, Lee S, L'Ecuyer T, Kato S, Loeb N, Ma H-Y (2013) Characterizing and understanding radiation budget biases in CMIP3/CMIP5 GCMs, contemporary GCM, and reanalysis. J Geophys Res Atmos 118:81668184. https://doi.org/10.1002/jgrd.50378

Li X, Tao W-K, Matsui T, Liu C, Masunaga H (2010) Improving a spectral bin microphysical scheme using TRMM satellite observations. Q J R Meteorol Soc 136:382-399. https://doi.org/10.1002/qj.569

Li Y, Thompson DWJ, Bony S (2015) The influence of atmospheric cloud radiative effects on the large-scale atmospheric circulation. J Clim 28:7263-7278, https://doi.org/10.1175/JCLI-D-14-00825.1

Lin YL, Farley RD, Orville HD (1983) Bulk parameterization of the snow field in a cloud model. J Appl Meteorol 22:1065-1092. https://doi.org/10.1175/15200450(1983)022<1065:BPOTSF>2.0.CO;2

Liou K-N (2002) An introduction to atmospheric radiation. Academic Press, San Diego 
Liu R, Liou K, Su H, Gu Y, Zhao B (2017) High cloud variations with surface temperature from 2002 to 2015: contributions to atmospheric radiative cooling rate and precipitation changes. J Geophys Res Atmos 122:5457-5471. https://doi.org/10.1002/2016JD026303

Locatelli JD, Hobbs PV (1974) Fall speeds and masses of solid precipitation particles. J Geophys Res 79:2185-2197. https://doi.org/10.1029/ JC079i015p02185

Loeb NG, Wielicki BA, Doelling DR, Smith GL, Keyes DF, Kato S, Manalo-Smith N, Wong T (2009) Toward optimal closure of the Earth's top-of-atmosphere radiation budget. J Clim 22:748-766. https://doi.org/10.1175/2008JCLI2637.1

Masunaga H, Kummerow CD (2005) Combined radar and radiometer analysis of precipitation profiles for a parametric retrieval algorithm. J Atmos Ocean Technol 22:909-929. https://doi.org/10.1175/JTECH1751.1

Meyers MP, DeMott PJ, Cotton WR (1992) New primary ice-nucleation parameterizations in an explicit cloud model. J Appl Meteorol 31:708-720. https://doi.org/10.1175/1520-0450(1992)031<0708:NPINPI>2.0.CO;2

Mitchell DL (1996) Use of mass and area-dimensional power laws for determining precipitation particle terminal velocities. J Atmos Sci 53:17101723. https://doi.org/10.1175/1520-0469(1996)053<1710:UOMAAD>2.0.CO;2

Miura H, Satoh M, Nasuno T, Noda AT, Oouchi K (2007) A madden-Julian oscillation event realistically simulated by a global cloud-resolving model. Science 318:1763-1765. https://doi.org/10.1126/science.1148443

Miura H, Tomita H, Nasuno T, Iga S, Satoh M, Matsuno T (2005) A climate sensitivity test using a global cloud resolving model under an aqua planet condition. Geophys Res Lett 32:L19717. https://doi.org/10.1029/ 2005GL023672

Mizuta R (2012) Intensification of extratropical cyclones associated with the polar jet change in the CMIP5 global warming projections. Geophys Res Lett 39: L19707. https://doi.org/10.1029/2012GL053032

Mizuta R, Adachi Y, Yukimoto S, Kusunoki S (2008) Estimation of the future distribution of sea surface temperature and sea ice using the CMIP3 multimodel ensemble mean. In: Technical reports of the meteorological research institute, vol. 56. Meteorological Research Institute, Tsukuba. https://doi.org/ 10.11483/mritechrepo.56

Nakajima TY, Suzuki K, Stephens GL (2010) Droplet growth in warm water clouds observed by the A-train. Part II: a multisensor view. J Atmos Sci 67:18971907. https://doi.org/10.1175/2010JAS3276.1

Nakanishi M, Niino H (2006) An improved Mellor-Yamada level-3 model: its numerical stability and application to a regional prediction of advection fog. Bound-Layer Meteorol 119:397-407. https://doi.org/10.1007/s10546-005-9030-8

Naud CM, Del Genio AD, Bauer M, Kovari W (2010) Cloud vertical distribution across warm and cold fronts in cloudsat-CALIPSO data and a general circulation model. J Clim 23:3397-3415. https://doi.org/10.1175/2010JCLI3282.1

Nishizawa S, Yashiro H, Sato Y, Miyamoto Y, Tomita H (2015) Influence of grid aspect ratio on planetary boundary layer turbulence in large-eddy simulations. Geosci Model Dev 8:3393-3419. https://doi.org/10.5194/gmd-83393-2015

Noda AT, Oouchi K, Satoh M, Tomita H (2012) Quantitative assessment of diurnal variation of tropical convection simulated by a global nonhydrostatic model without cumulus parameterization. J Clim 25:5119-5134. https://doi.org/10. 1175/JCLI-D-11-00295.1

Noda AT, Oouchi K, Satoh M, Tomita H, Iga S, Tsushima Y (2010) Importance of the subgrid-scale turbulent moist process: cloud distribution in global cloudresolving simulations. Atmos Res 96:208-217. https://doi.org/10.1016/j. atmosres.2009.05.007

Noda AT, Satoh M (2014) Intermodel variances of subtropical stratocumulus environments simulated in CMIP5 models. Geophys Res Lett 41:7754-7761. https://doi.org/10.1002/2014GL061812

Noda AT, Satoh M, Yamada Y, Kodama C, Miyakawa T, Seiki T (2015) Cold and warm rain simulated using a global nonhydrostatic model without cumulus parameterization, and its responses to global warming. J Meteorol Soc Japan 93:181-197. https://doi.org/10.2151/jmsj.2015-010

Noda AT, Satoh M, Yamada Y, Kodama C, Seiki T (2014) Responses of tropical and subtropical high-cloud statistics to global warming. J Clim 27:7753-7768. https://doi.org/10.1175/JCLI-D-14-00179.1

Noda AT, Seiki T, Satoh M, Yamada Y (2016) High cloud size dependency in the applicability of the fixed anvil temperature hypothesis using global nonhydrostatic simulations. Geophys Res Lett 43:2307-2314. https://doi.org/10. 1002/2016GL067742

Ohno T, Satoh M (2018) Roles of cloud microphysics on cloud responses to sea surface temperatures in radiative-convective equilibrium experiments using a high-resolution global nonhydrostatic model. J Adv Model Earth Syst 10. https://doi.org/10.1029/2018MS001386

Ono A (1969) The shape and riming properties of ice crystals in natural clouds. J Atmos Sci 26:138-147. https://doi.org/10.1175/1520-0469(1969)026<0138: TSARPO > 2.0.CO;2

Phillips VTJ, Donner LJ, Garner ST (2007) Nucleation processes in deep convection simulated by a cloud-system-resolving model with doublemoment bulk microphysics. J Atmos Sci 64:738-761. https://doi.org/10.1175/ JAS3869.1

Posselt DJ, Stephens GL, Miller M (2008) CLOUDSAT: adding a new dimension to a classical view of extratropical cyclones. Bull Am Meteorol Soc 89:599-609. https://doi.org/10.1175/BAMS-89-5-599

Pruppacher HR, Klett JD (1997) Microphysics of clouds and precipitation. Kluwer Academic Publishers, Dordrecht

Ren C, MacKenzie AR (2005) Cirrus parameterization and the role of ice nuclei. Q J R Meteorol Soc 131:1585-1605. https://doi.org/10.1256/qj.04.126

Rodgers EB, Adler RF, Pierce HF (2000) Contribution of tropical cyclones to the North Pacific climatological rainfall as observed from satellites. J Appl Meteorol 39:1658-1678. https://doi.org/10.1175/1520-0450(2000)039<1658: COTCTT>2.0.CO;2

Roh W, Satoh M (2014) Evaluation of precipitating hydrometeor parameterizations in a single-moment bulk microphysics scheme for deep convective systems over the tropical Central Pacific. J Atmos Sci 71:26542673. https://doi.org/10.1175/JAS-D-13-0252.1

Roh W, Satoh M, Nasuno T (2017) Improvement of a cloud microphysics scheme for a global nonhydrostatic model using TRMM and a satellite simulator. J Atmos Sci 74:167-184. https://doi.org/10.1175/JAS-D-16-0027.1

Sato Y, Nakajima TY, Nakajima T (2012) Investigation of the vertical structure of warm-cloud microphysical properties using the cloud evolution diagram, CFODD, simulated by a three-dimensional spectral bin microphysical model. J Atmos Sci 69:2012-2030. https://doi.org/10.1175/ JAS-D-11-0244.1

Sato Y, Nishizawa S, Yashiro H, Miyamoto Y, Kajikawa Y, Tomita H (2015) Impacts of cloud microphysics on trade wind cumulus: which cloud microphysics processes contribute to the diversity in a large eddy simulation? Prog Earth Planet Sci 2(1):23. https://doi.org/10.1186/s40645-015-0053-6

Satoh M, Iga S, Tomita H, Tsushima Y, Noda AT (2012) Response of upper clouds due to global warming tested by a global atmospheric model with explicit cloud processes. J Clim 25:2178-2191. https://doi.org/10.1175/JCLI-D-1100152.1

Satoh M, Inoue T, Miura H (2010) Evaluation of cloud properties of global and local cloud system resolving model using CALIPSO and CloudSat simulators. J Geophys Res 115:D00H14. https://doi.org/10.1029/2009JD012247

Satoh M, Matsuno T, Tomita H, Miura H, Nasuno T, Iga S (2008) Nonhydrostatic icosahedral atmospheric model (NICAM) for global cloud resolving simulations. J Comput Phys 227:3486-3514. https://doi.org/10.1016/j.jcp.2007.02.006

Satoh M, Tomita H, Yashiro H, Kajikawa Y, Miyamoto Y, Yamaura T, Miyakawa T, Nakano M, Kodama C, Noda AT, Nasuno T, Yamada Y, Fukutomi Y (2017) Outcomes and challenges of global high-resolution non-hydrostatic atmospheric simulations using K computer. Prog Earth Planet Sci 4:13. https://doi.org/10.1186/s40645-017-0127-8

Satoh M, Tomita H, Yashiro H, Miura H, Kodama C, Seiki T, Noda AT, Yamada Y, Goto D, Sawada M, Miyoshi T, Niwa Y, Hara M, Ohno Y, Iga S, Arakawa T, Inoue T, Kubokawa H (2014) The non-hydrostatic icosahedral atmospheric model: description and development. Prog Earth Planet Sci 1:18. https://doi. org/10.1186/s40645-014-0018-1

Satoh M, Yamada Y, Sugi M, Kodama C, Noda AT (2015) Constraint on future change in global frequency of tropical cyclones due to global warming. J Meteorol Soc Japan 93:489-500. https://doi.org/10.2151/jmsj.2015-025

Schneider T, Teixeira J, Bretherton CS, Brient F, Pressel KG, Schär C, Siebesma AP (2017) Climate goals and computing the future of clouds. Nat Clim Chang 7: 3-5. https://doi.org/10.1038/nclimate3190

Scoccimarro E, Gualdi S, Villarini G, Vecchi GA, Zhao M, Walsh K, Navarra A (2014) Intense precipitation events associated with landfalling tropical cyclones in response to a warmer climate and increased $\mathrm{CO}_{2}$. J Clim 27:4642-4654. https://doi.org/10.1175/JCLI-D-14-00065.1

Seifert A, Beheng KD (2006) A two-moment cloud microphysics parameterization for mixed-phase clouds. Meteorog Atmos Phys 92:45-66. https://doi.org/10. 1007/s00703-005-0112-4

Seiki T, Kodama C, Noda AT, Satoh M (2015a) Improvement in global cloudsystem resolving simulations by using a double-moment bulk cloud 
microphysics scheme. J Clim 28:2405-2419. https://doi.org/10.1175/JCLID-14-00241.1

Seiki T, Kodama C, Satoh M, Hashino T, Hagihara Y, Okamoto H (2015b) Vertical grid spacing necessary for simulating tropical cirrus clouds with a high-resolution atmospheric general circulation model. Geophys Res Lett 42:4150-4157. https://doi.org/10.1002/2015GL064282

Seiki T, Nakajima T (2014) Aerosol effects of the condensation process on a convective cloud simulation. J Atmos Sci 71:833-853. https://doi.org/10.1175/ JAS-D-12-0195.1

Seiki T, Satoh M, Tomita H, Nakajima T (2014) Simultaneous evaluation of ice cloud microphysics and nonsphericity of the cloud optical properties using hydrometeor video sonde and radiometer sonde in situ observations. J Geophys Res Atmos 119:6681-6701. https://doi.org/10. 1002/2013JD021086

Sekiguchi M, Nakajima T (2008) A k-distribution-based radiation code and its computational optimization for an atmospheric general circulation model. J Quant Spectrosc Radiat Transf 109:2779-2793. https://doi.org/10.1016/j.jgsrt. 2008.07.013

Shipway BJ, Hill AA (2012) Diagnosis of systematic differences between multiple parametrizations of warm rain microphysics using a kinematic framework. Q J R Meteorol Soc 138:2196-2211. https://doi.org/10.1002/qj.1913

Siebesma AP, Bretherton CS, Brown A, Chlond A, Cuxart J, Duynkerke PG, Jiang H, Khairoutdinov M, Lewellen D, Moeng C-H, Sanchez E, Stevens B, Stevens DE (2003) A large eddy simulation intercomparison study of shallow cumulus convection. J Atmos Sci 60:1201-1219

Soden BJ, Held IM (2006) An assessment of climate feedbacks in coupled ocean atmosphere models. J Clim 19:3354-3360. https://doi.org/10.1175/JCLI3799.1

Stevens B, Ackerman AS, Albrecht BA, Brown AR, Chlond A, Cuxart J, Duynkerke PG, Lewellen DC, Macvean MK, Neggers RAJ, Sánchez E, Siebesma AP, Stevens DE (2001) Simulations of trade wind cumuli under a strong inversion. J Atmos Sci 58:1870-1891. https://doi.org/10.1175/15200469(2001)058<1870:SOTWCU>2.0.CO;2

Stevens B, Bony S (2013) What are climate models missing? Science 340:10531054. https://doi.org/10.1126/science.1237554

Stevens B, Moeng C-H, Ackerman SD, Bretherton CS, Chlon A, de Roode S, Edwards J, Golaz J, Jiang H, Khairoutdinov M, Kirkpatrick MP, Lewellen DC, Lock A, Müller F, Stevens DE, Whelan E, Zhu P (2005) Evaluation of largeeddy simulations via observations of nocturnal marine stratocumulus. Mon Weather Rev 133:1443-1462. https://doi.org/10.1175/MWR2930.1

Su H, Jiang JH, Neelin JD, Shen TJ, Zhai C, Yue Q, Wang Z, Huang L, Choi Y-S, Stephens GL, Yung YL (2017) Tightening of tropical ascent and high clouds key to precipitation change in a warmer climate. Nat Commun 8:15771. https://doi.org/10.1038/ncomms15771

Suzuki K, Nakajima T, Nakajima TY, Khain AP (2010a) A study of microphysical mechanisms for correlation patterns between droplet radius and optical thickness of warm clouds with a spectral bin microphysics cloud model. J Atmos Sci 67:1126-1141. https://doi.org/10.1175/2009JAS3283.1

Suzuki K, Nakajima TY, Stephens GL (2010b) Particle growth and drop collection efficiency of warm clouds as inferred from joint CloudSat and MODIS observations. J Atmos Sci 67:3019-3032. https://doi.org/10.1175/ 2010JAS3463.1

Suzuki K, Stephens G (2008) Global identification of warm cloud microphysical processes with combined use of A-train observations. Geophys Res Lett 35: L08805. https://doi.org/10.1029/2008GL033590

Suzuki K, Stephens G, Bodas-Salcedo A, Wang M, Golaz J-C, Yokohata T, Koshiro T (2015) Evaluation of the warm rain formation process in global models with satellite observations. J Atmos Sci 72:3996-4014. https://doi.org/10.1175/JASD-14-0265.1

Takata K, Emori S, Watanabe T (2003) Development of the minimal advanced treatments of surface interaction and runoff. Glob Planet Chang 38:209-222. https://doi.org/10.1016/S0921-8181(03)00030-4

Taylor KE, Williamson D, Zwiers F (2000) The sea surface temperature and sea-ice concentration boundary conditions for AMIP II simulations. In: Program for climate model diagnosis and intercomparison report 60. Lawrence Livermore National Laboratory, Livermore

Tomita $\mathrm{H}$ (2008) New microphysical schemes with five and six categories by diagnostic generation of cloud ice. J Meteorol Soc Japan 86A:121-142. https://doi.org/10.2151/jmsj.86A.121

Tomita H, Satoh M (2004) A new dynamical framework of nonhydrostatic global model using the icosahedral grid. Fluid Dyn Res 34:357-400. https://doi.org/ 10.1016/j.fluiddyn.2004.03.003
Tselioudis G, Rossow WB (2006) Climate feedback implied by observed radiation and precipitation changes with midlatitude storm strength and frequency. Geophys Res Lett 33:L02704. https://doi.org/10.1029/2005GL024513

Tsushima Y, Iga S, Tomita H, Satoh M, Noda AT, Webb M (2014) High cloud increase in a perturbed SST experiment with a global nonhydrostatic model including explicit convective processes. J Adv Model Earth Syst 6:571-585. https://doi.org/10.1002/2013MS000301

van Zanten MC, Stevens B, Nuijens L, Siebesma AP, Ackerman AS, Burnet F, Cheng A, Couvreux F, Jiang H, Khairoutdinov M, Kogan Y, Lewellen DC, Mechem D, Nakamura K, Noda A, Shipway BJ, Slawinska J, Wang S, Wyszogrodzki A (2011) Controls on precipitation and cloudiness in simulations of trade-wind cumulus as observed during RICO. J Adv Model Earth Syst 3:M06001. https://doi.org/10.1029/2011MS000056

Vial J, Dufresne J-L, Bony S (2013) On the interpretation of inter-model spread in CMIP5 climate sensitivity estimates. Clim Dyn 41:3339-3362. https://doi.org/ 10.1007/s00382-013-1725-9

Waliser DE, Li J-LF, Woods CP, Austin RT, Bacmeister J, Chern J, Genio AD, Jiang $J H$, Kuang Z, Minnis P, Platnick S, Rossow WB, Stephens GL, Sun-Mack S, Tao W-K, Tompkins AM, Vane DG, Walker C, Wu D (2009) Cloud ice: a climate model challenge with signs and expectations of progress. I Geophys Res 114:D00A2. https://doi.org/10.1029/2008JD010015

Webb M, Senior C, Bony S, Morcrette JJ (2001) Combining and ERBE and ISCCP data to assess clouds in the Hadley Centre, ECMWF and LMD atmospheric climate models. Clim Dyn 17:905-922. https://doi.org/10.1007/s003820100157

Williamson DL, Blackburn M, Nakajim K, Ohfuchi W, Takahashi YO, Hayashi Y-Y, Nakamura H, Ishiwatari M, McGregor UL, Borth H, Wirth V, Frank H, Bechtold P, Wedi NP, Tomita H, Satoh S, Zhao M, Held IM, Suarez MJ, Lee M-I, Watanabe M, Kimoto M, Liu Y, Wang Z, Molod A, Rajendran K, Kitoh A, Stratton $R$ (2013) The aqua planet experiment (APE): response to changed SST profile. J Meteorol Soc Japan 91A:57-89. https://doi.org/10.2151/jmsj. 2013-A03

Wing AA, Reed KA, Satoh M, Stevens B, Bony S, Ohno T (2018) Radiativeconvective equilibrium model intercomparison project. Geosci Model Dev 11 : 793-813. https://doi.org/10.5194/gmd-2017-213

Wyant MC, Khairoutdinov M, Bretherton CS (2006) Climate sensitivity and cloud response of a GCM with a superparameterization. Geophys Res Lett 33: L06714. https://doi.org/10.1029/2005GL025464

Yamada Y, Oouchi K, Satoh M, Tomita H, Yanase W (2010) Projection of changes in tropical cyclone activity and cloud height due to greenhouse warming: global cloud-system-resolving approach. Geophys Res Lett 37:L07709. https:// doi.org/10.1029/2010GL042518

Yamada Y, Satoh M (2013) Response of ice and liquid water paths of tropical cyclones to global warming simulated by a global nonhydrostatic model with explicit cloud microphysics. J Clim 26:9931-9945. https://doi.org/10. 1175/JCLI-D-13-00182.1

Yamada Y, Satoh M, Sugi M, Kodama C, Noda AT, Nakano M, Nasuno T (2017) Response of tropical cyclone activity and structure to global warming in a high-resolution global nonhydrostatic model. J Clim 30:9703-9724. https:// doi.org/10.1175/JCLI-D-17-0068.1

Yin JH (2005) A consistent poleward shift of the storm tracks in simulations of 21st century climate. Geophys Res Lett 32:L18701. https://doi.org/10.1029/ 2005GL023684

Yoshizaki M, Iga S, Satoh M (2012) Eastward-propagating property of largescale precipitation systems simulated in the coarse-resolution NICAM and an explanation of its formation. SOLA 8:21-24. https://doi.org/10.2151/ sola.2012-006

Zelinka MD, Hartmann DL (2011) The observed sensitivity of high clouds to mean surface temperature anomalies in the tropics. J Geophys Res Atmos 116:D23103. https://doi.org/10.1029/2011JD016459

Zelinka MD, Klein SA, Hartmann DL (2012) Computing and partitioning cloud feedbacks using cloud property histograms. Part I: cloud radiative kernels. J Clim 25:3715-3735. https://doi.org/10.1175/JCLI-D-11-00248.1

Zelinka MD, Klein SA, Taylor KE, Andrews T, Webb MJ, Gregory JM, Forster PM (2013) Contributions of different cloud types to feedbacks and rapid adjustments in CMIP5. J Clim 26:5007-5027. https://doi.org/10.1175/JCLI-D12-00555.1

Zelinka MD, Randall DA, Webb MJ, Klein SA (2017) Clearing clouds of uncertainty. Nat Clim Chang 7:674-678. https://doi.org/10.1038/nclimate3402

Zelinka MD, Zhou C, Klein SA (2016) Insights from a refined decomposition of cloud feedbacks. Geophys Res Lett 43:9259-9269. https://doi.org/10.1002/ 2016GL069917 
Zhou C, Dessler AE, Zelinka MD, Yang P, Wang T (2014) Cirrus feedback on interannual climate fluctuations. Geophys Res Lett 41:9166-9173. https://doi. org/10.1002/2014GL062095

Zhou C, Zelinka MD, Klein SA (2016) Impact of decadal cloud variations on the Earth's energy budget. Nat Geosci 9:871-874. https://doi.org/10.1038/ ngeo2828

Submit your manuscript to a SpringerOpen ${ }^{\mathcal{O}}$ journal and benefit from:

- Convenient online submission

- Rigorous peer review

- Open access: articles freely available online

- High visibility within the field

- Retaining the copyright to your article

Submit your next manuscript at $\boldsymbol{\sim}$ springeropen.com 